\title{
Donor Effect on the Photoinduced Interfacial Charge Transfer Dynamics of $D-\pi-A$ Diketopyrrolopyrrole Dye Sensitizers Adsorbed on Titanium Dioxide
}

\author{
Hee-Won Bahng, ${ }^{\dagger, \S}$ Anders Hagfeldt, ${ }^{\ddagger, \S}$ and Jacques-E. Moser* ${ }^{*} \dagger, \S \odot$ \\ ${ }^{\dagger}$ Photochemical Dynamics Group, Institute of Chemical Sciences \& Engineering, École polytechnique fédérale de Lausanne, 1015 \\ Lausanne, Switzerland \\ ${ }^{\ddagger}$ Laboratory of Photomolecular Science, Institute of Chemical Sciences \& Engineering, École polytechnique fédérale de Lausanne, \\ 1015 Lausanne, Switzerland \\ ${ }^{\S}$ Lausanne Centre for Ultrafast Science (LACUS), École polytechnique fédérale de Lausanne, 1015 Lausanne, Switzerland
}

\section{Supporting Information}

\begin{abstract}
In this report, we investigate the effects of a strong electron-donating group on the electron injection and recombination processes of diketopyrrolopyrrole (DPP)-sensitized $\mathrm{TiO}_{2}$ films by comparing the dynamics of triphenylamine donor-installed DPP_A and donor-absent DPP_R dyes. We show that the electron-donating group enhances the intramolecular charge transfer (ICT) characteristics of DPP_A, as demonstrated by a significant spectral redshift in the steady-state measurement of DPP_A compared to that of DPP_R. By comparing the ultrafast transient behaviors of the dyecoated films through femtosecond transient absorption (fs-TA) measurements, we provide insight into the high efficiency of DPP_A: most of the electrons from DPP_A are injected into the conduction band of $\mathrm{TiO}_{2}$ within the time resolution of $\mathrm{TA}(<150 \mathrm{fs})$,

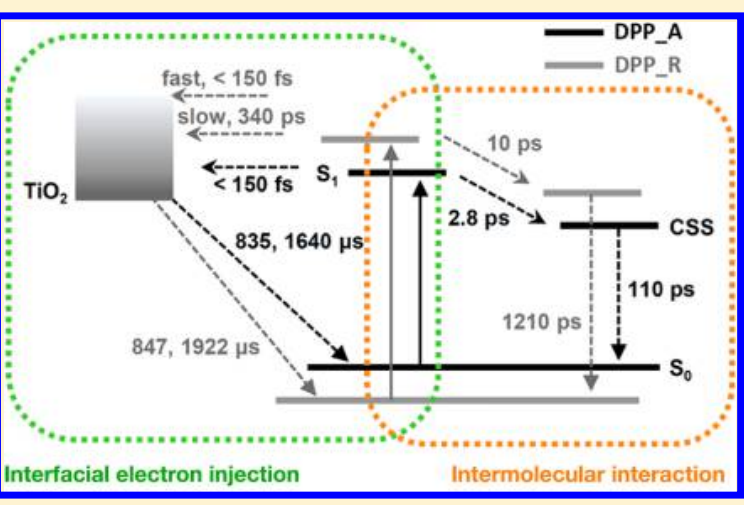
while DPP_R displays a biphasic electron injection process of $c a .340$

ps (including slow decay). Additionally, due to the existence of lateral intermolecular interactions on $\mathrm{TiO}_{2}$, a phenomenon that takes place on the time scale of several picoseconds and was only recently investigated in our prior work, the charge injection process becomes inefficient. More precisely, lateral interactions act as a barrier to efficient charge injection when the electron donor is absent by opening another faster pathway before the delayed electron injection. Through further flash photolysis measurements, we demonstrate that this intermolecular interaction affects the recombination of electrons with dye cations, causing delayed recombination decay components.
\end{abstract}

\section{INTRODUCTION}

As one of the most efficient structures in organic dye sensitizers, the donor- $\pi$ bridge-acceptor $(D-\pi-A)$ system has drawn considerable interest due to its significant extinction coefficient in a wide absorption range, easy tunability of the energy levels achieved by varying the molecular moieties, low fabrication costs, and environmental friendliness compared to traditionally used ruthenium complex sensitizers. ${ }^{1-3}$

Especially, blue-colored diketopyrrolopyrrole (DPP), where the DPP core acts as a $\pi$-bridge in the $\mathrm{D}-\pi-\mathrm{A}$ architecture, is an attractive dye sensitizer for solar cells. Its attractiveness comes from its high performance and unique blue color. ${ }^{4-7}$ Compared with other blue sensitizers, such as squaraine, whose power conversion efficiency (PCE) is less than $5.5 \%$, 8,9 DPPs have enhanced PCEs of approximately $10 \%$, as they benefit from additional absorption in the spectral domain below 550 nm. ${ }^{10}$ These properties make DPP-based dyes promising photosensitizers, naturally making it important to understand the fundamental characteristics of DPP.
Because of the importance of DPP sensitizers, many investigations have been performed on their electrochemical and photovoltaic characteristics. One of the popular ways to control the characteristics of DPP sensitizers is to strategically modulate the donor moiety linked to the DPP core because one can affect the absorbance of red light by controlling the optical excitation gap between frontier orbitals. ${ }^{11}$ With this approach, many DPP sensitizers with various donor groups, such as triphenylamine and indoline-based derivatives, have been developed and investigated. ${ }^{10,12-15}$ However, the kinetic aspects of this approach are poorly understood, especially in regards to the effect of the donor on the electron transfer kinetics.

The influence of the donor moiety on the intermolecular interactions between neighboring dye molecules has already

Received: May 21, 2018

Revised: July 29, 2018

Published: August 8, 2018 
been scrutinized from a photophysical point of view, revealing that the type of exciton involved in the interaction changes from a charge transfer exciton to an excimer-like exciton when the electron donor is absent. ${ }^{16}$ Considering the time scale of lateral interactions, it is highly likely that these interactions compete with interfacial charge injection, acting as one of the efficiency-determining factors.

Despite the vast amount of research conducted, the effect of the donor on the electron transfer kinetics of DPP sensitizers has not been specifically explored. However, studies on this effect are necessary to fully understand the structure-property relationship of the system. Once the photophysical requirements for a certain application are clearly understood, molecular engineering designed to embody these characteristics can be made possible.

In this report, we focus on the photophysical effects of interfacial electron injection from a dye to $\mathrm{TiO}_{2}$ and the recombination processes upon photoexcitation. To comprehend the charge transfer dynamics of DPP-sensitized solar cells step by step, we conduct kinetic studies on the donorcontaining push-pull dye-sensitizer DPP_A by comparing it with the parent dye molecule DPP_R, which lacks the donor moiety. The structures of the dyes are shown in Figure 1. Both

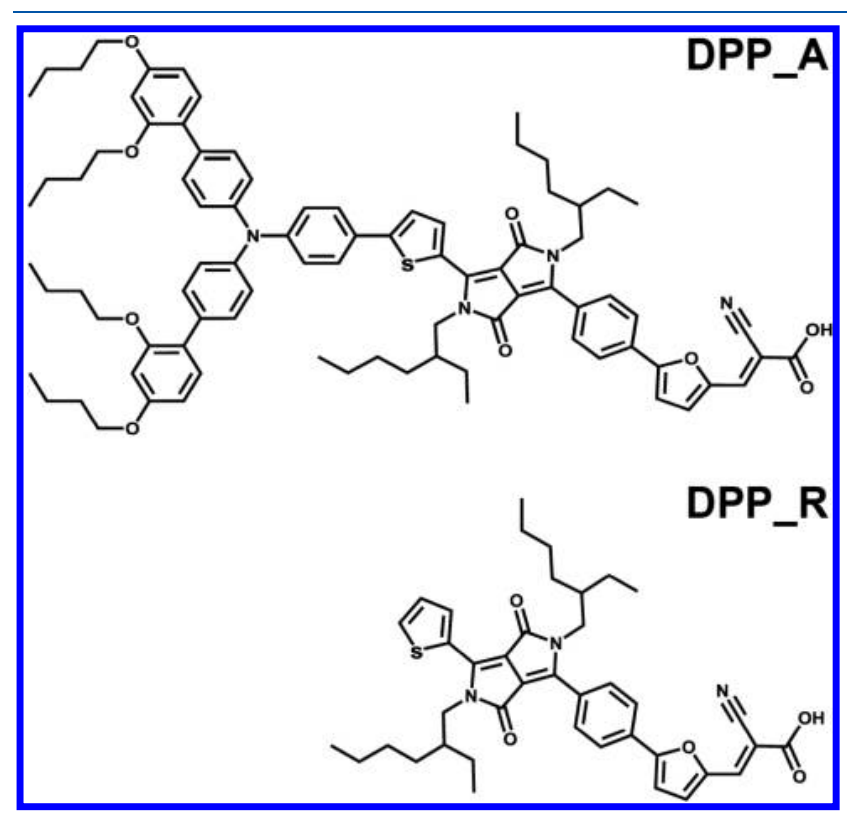

Figure 1. Molecular structures of the dyes DPP_A and DPP_R.

dyes were adsorbed on the surface of mesoporous $\mathrm{TiO}_{2}$. For the purpose of characterization, we measured the steady-state and time-resolved femtosecond transient absorption (fs-TA) spectra with flash photolysis measurements.

The experimental results reveal a significantly enhanced intramolecular charge transfer (ICT) characteristic for DPP A induced by the introduced electron donor relative to that of DPP_R in the steady-state measurements. Additionally, based on observation of the fs-TA behaviors, most of the electrons were injected from the DPP_A dye into $\mathrm{TiO}_{2}$ within the time resolution of TA $(<150 \mathrm{fs})$, whereas the DPP $\mathbf{R}$ dye displays an additional delayed route with a time constant of ca. 340 ps. We argue that the delayed electron injection of DPP_R, originating from a reduced ICT state, is responsible for the low efficiency of the donor-absent DPP-sensitized cell. Interestingly, the remaining neutral dye molecules undergo lateral intermolecular interactions, which influence the recombination of electrons with the dye cations, as demonstrated by the observation of an extended recombination time in nanosecond flash photolysis measurements.

\section{METHODS}

2.1. Sample Preparation. Solution Samples. The DPP A dye used in the study was purchased from Dyenamo $A B$ (product code DN-F10 "Dyenamo blue"), while DPP_R was synthesized according to a typical synthetic route. ${ }^{-16}$ DPP_A and DPP_R were dissolved in a 4-tert-butanol/ acetonitrile mixture $(1: 1 \mathrm{v} / \mathrm{v})^{10}$ and 4-tert-butanol, respectively.

Film Samples. Mesoporous substrates were prepared with homemade $\mathrm{Al}_{2} \mathrm{O}_{3}$ and commercial $\mathrm{TiO}_{2}$ (Dyesol Ltd.) pastes. The average particle diameters of the $\mathrm{Al}_{2} \mathrm{O}_{3}$ and $\mathrm{TiO}_{2}$ nanoparticles in the pastes were, respectively, 20 and $18 \mathrm{~nm}$. Samples intended for spectroscopic experiments were prepared by screen printing the respective pastes onto FTOcoated transparent glass substrates (Tec15, Pilkington). Alumina and titania layers were sintered for $30 \mathrm{~min}$ at 450 ${ }^{\circ} \mathrm{C}$ to yield $4.5-\mu \mathrm{m}$-thick mesoporous films with porosities of 0.67 and 0.625 , respectively. Dying of the films was achieved by dipping them into a $50 \mu \mathrm{M}$ solution of the dye. To prevent aggregation upon adsorption of the dye molecules on the surface, chenodeoxycholic acid (CDCA, Sigma-Aldrich) was used as a coadsorbant at a concentration 50 times larger (2.5 $\mathrm{mM}$ ) than that of the dye solution. ${ }^{18}$ Samples were kept in the dark at room temperature for less than $3 \mathrm{~h}$ before measurement.

2.2. Steady-State Measurements. Steady-state absorption spectra were obtained by using a UV-visible spectrometer (Cary 1E, Varian), and fluorescence spectra were obtained by using a spectrofluorometer (LS 50B, PerkinElmer).

2.3. Femtosecond Transient Absorption Measurements. A fs-TA spectrometer based on a Ti:sapphire chirped pulse amplifier system (Clark-MXR, CPA-2001) was used to record the TA spectra. The laser provided 150 fs-duration pulses at a fundamental wavelength of $780 \mathrm{~nm}$ and repetition rate of $1 \mathrm{kHz}$. The pump beam was generated by frequency doubling part of the laser output on a nonlinear beta barium borate (BBO) crystal $(390 \mathrm{~nm})$, while the remaining beam was sent to a sapphire plate to produce a broadband white light continuum $(420-770 \mathrm{~nm})$ used as the probe beam. Additionally, the pump excitation wavelength was tuned by a two-stage noncollinear optical parametric amplifier (NOPA). The NOPA could achieve wavelengths from 450 to $1250 \mathrm{~nm}$ with 6-14 $\mu \mathrm{J} /$ pulse by using $150 \mu \mathrm{J} /$ pulse of the Ti:sapphire output. In the first stage, to select a color from white light, a white light seed beam obtained from a sapphire plate and a frequencydoubled pump beam $(390 \mathrm{~nm})$ were focused on a nonlinear BBO crystal under phase-matching conditions. Next, in the second stage, this selected beam was amplified 6 times through another BBO crystal. The outcoming pulse was compressed by a pair of SF10 prisms to correct for group velocity dispersion (GVD). The time delay between the pump and the probe beams was carefully controlled by making the pump beam travel along a variable optical delay with the use of a motorized translation stage (Physik Instrumente, M531 PD). To obtain the time-resolved TA difference signal $(\Delta A)$ at a specific time, the pump pulses were chopped at $500 \mathrm{~Hz}$, and the absorption spectral intensities were saved alternatingly with and without the pump pulse. The probe beam was split into two parts, with 
one part probing the samples and a second part passing alongside and being used as a reference to account for intensity fluctuations. The probe and reference pulses were detected shot by shot with two respective spectrographs (Andor Technology) equipped with $512 \times 58$ pixel back-thinned CCD cameras (Hamamatsu, S07030-0906). To obtain a satisfactory signal-to-noise ratio, measurements were typically averaged over 2500 shots. The polarization angle between the pump and the probe beams was set to the magic angle $\left(54.7^{\circ}\right)$ using a Glan-laser polarizer with a half-wave retarder to prevent polarization-dependent signals. The pump energy fluences on the film samples were limited to a maximum of $140 \mu \mathrm{J} / \mathrm{cm}^{2}$. White light chirp correction was conducted by using the Kerr gating technique.

2.4. Flash Photolysis Measurements. Nanosecond flash photolysis was used to monitor the microsecond to millisecond dynamics. Excitation pulses were generated by a broadband optical parametric oscillator (OPO, GWU-355) pumped by a frequency-tripled $(355 \mathrm{~nm}) \mathrm{Nd}$ :YAG Q-switched laser (Ekspla, NT-342) with a $20 \mathrm{~Hz}$ repetition rate. The pump fluence at the sample was limited to $<30 \mu \mathrm{J} / \mathrm{cm}^{2}$, which ideally corresponds to an average of less than 1 electron injected per $\mathrm{TiO}_{2}$ particle, by attenuating the laser beam with gray filters and expanding it with a diverging lens. A cw Xe arc lamp was used to generate the probe beam. This beam was passed through various filters, a monochromator and multiple lenses before reaching the sample. After going through the latter, a collecting lens, and a cutoff filter, the probe beam was finally focused onto the entrance slit of a second monochromator and detected by a fast photomultiplier tube (R9910, Hamamatsu), only three dynodes of which were activated. A broadband oscilloscope (Tektronix, DPO 7104C) was used to record the induced transient voltage signal. Data acquisition was typically averaged over 3000 laser shots to obtain a satisfactory signal-to-noise ratio. The resulting transient absorbance sensitivity was $<10^{-4}$ $\Delta A$.

\section{RESULTS AND DISCUSSION}

3.1. Absorption and Fluorescence Spectra. Figure 2 shows the normalized steady-state absorption and fluorescence spectra of DPP_A and DPP_R on $\mathrm{Al}_{2} \mathrm{O}_{3}$ (a) and $\mathrm{TiO}_{2}$ (b). Significant bathochromic shifts are observed when the triphenylamine electron donor is present. This shift originates from the enhanced ICT characteristic of DPP_A, which increases charge delocalization, resulting in a ca. $0.18 \mathrm{eV}$ decrease in the optical excitation energy. ${ }^{19}$ Table 1 lists the optical parameters from the steady-state results.

In Figure 2, blueshifts in the ICT absorption bands are observed in the visible domains of both the DPP_A and DPP_R films relative to the same bands of the dyes in solution (see Supporting Information, Figure S1). These shifts are attributed to the adsorption of the dyes on the surface and subsequent deprotonation of their cyanoacrylic anchoring group. $^{20}$

Compared to the emission spectra of the dyes on $\mathrm{Al}_{2} \mathrm{O}_{3}$, the fluorescence of the dyes on $\mathrm{TiO}_{2}$ is substantially quenched because of the occurrence of efficient electron transfer from the dyes to $\mathrm{TiO}_{2}{ }^{20,21}$

3.2. Femtosecond Transient Absorption Measurements. Photophysical Dynamics of DPP_A on $\mathrm{TiO}_{2}$ Films. First, the ultrafast transient dynamics of DPP_A adsorbed on $\mathrm{TiO}_{2}$ films were investigated by fs-TA spectroscopy. To avoid the effect of the excitation photon fluence on the dynamics, the

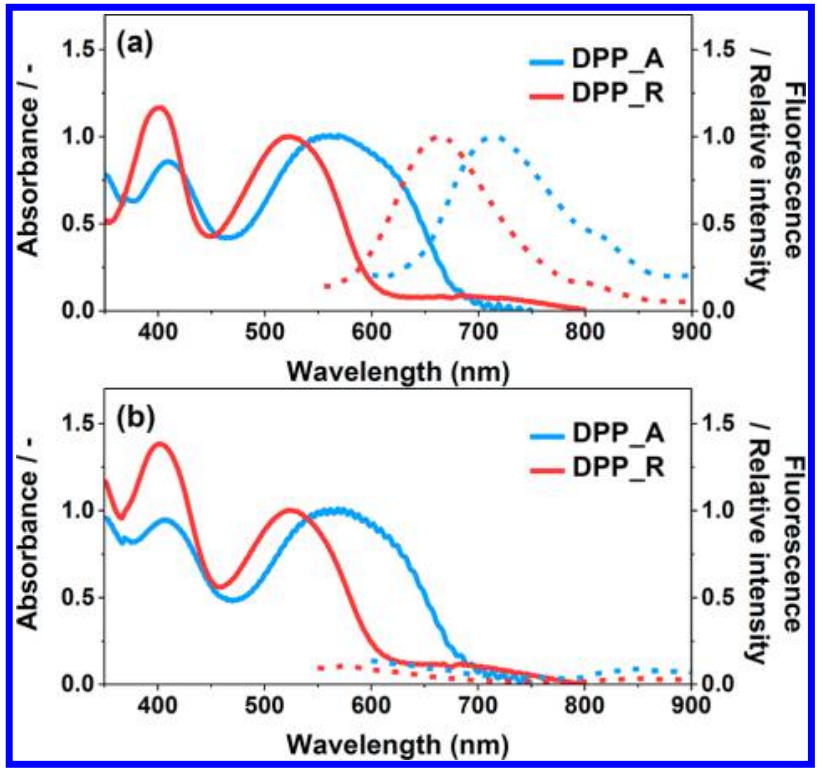

Figure 2. Normalized steady-state absorption and fluorescence spectra of DPP_A and DPP_R on $\mathrm{Al}_{2} \mathrm{O}_{3}$ (a) and $\mathrm{TiO}_{2}$ (b). Fluorescence spectra were obtained by exciting the sample at $480 \mathrm{~nm}$ and normalized to the maximum values measured on $\mathrm{Al}_{2} \mathrm{O}_{3}$.

Table 1. Steady-State Photophysical Values of DPP_A and DPP_R on Mesoporous $\mathrm{Al}_{2} \mathrm{O}_{3}$ and $\mathrm{TiO}_{2}$ Films

\begin{tabular}{lcccccc} 
& \multicolumn{2}{c}{ DPP_A } & & \multicolumn{2}{c}{ DPP_R } \\
\cline { 2 - 3 } \cline { 5 - 6 } & $\mathrm{Al}_{2} \mathrm{O}_{3}$ & $\mathrm{TiO}_{2}$ & & $\mathrm{Al}_{2} \mathrm{O}_{3}$ & $\mathrm{TiO}_{2}$ \\
$\mathrm{Abs}_{\max }$ wavelength $[\mathrm{nm}]$ & 561 & 569 & & 522 & 523 \\
$\mathrm{Fl}_{\max }$ wavelength $[\mathrm{nm}]$ & 711 & - & & 661 & - \\
Stokes shift $\left[\mathrm{cm}^{-1}\right]$ & 3761 & - & & 4028 & - \\
\hline
\end{tabular}

pump fluence was carefully controlled to ensure that an average of less than one electron was injected per nanoparticle, forming one oxidized dye species for each particle. ${ }^{22}$

Figure 3a exhibits the fs-TA spectra of DPP A at selected pump-probe delay times obtained using a $390 \mathrm{~nm}$ excitation source. At early times, a ground-state bleaching (GSB) band appears at $585 \mathrm{~nm}$, corresponding to a $16 \mathrm{~nm}$ redshift compared to the maximum band in the steady-state absorption spectrum of DPP_A. This large spectral shift indicates that significant injection of electrons from the dye into $\mathrm{TiO}_{2}$ occurs within the time resolution of the experiment $(<150 \mathrm{fs})$, which is commonly observed for other organic dye-sensitized cells. $^{23-25}$ Two positive excited-state absorption (ESA) bands are observed on each side of the GSB band. An earlier study on DPP_A dye both in solution and on an inert $\mathrm{Al}_{2} \mathrm{O}_{3}$ surface revealed that the blue-sideband originates from the excitedstate relaxation of the dye, while the red-sideband is ascribed to intermolecular interactions between dye molecules. ${ }^{16}$ However, when the dye molecules are adsorbed on $\mathrm{TiO}_{2}$, whose conduction band edge is lower than the excited state energy level of the dye, ultrafast interfacial electron injection dominates the excited-state dynamics upon photoexcitation.

Parts $\mathrm{c}$ and $\mathrm{d}$ of Figure 3 exhibit the kinetic profiles at selected wavelengths of 470 and $760 \mathrm{~nm}$; these profiles demonstrate the occurrence of electron injection, generating oxidized dye molecules that exist until they recombine with electrons in the conduction band of $\mathrm{TiO}_{2}$. Compared to the kinetic profiles of the dye on the $\mathrm{Al}_{2} \mathrm{O}_{3}$ film, those of the dye 


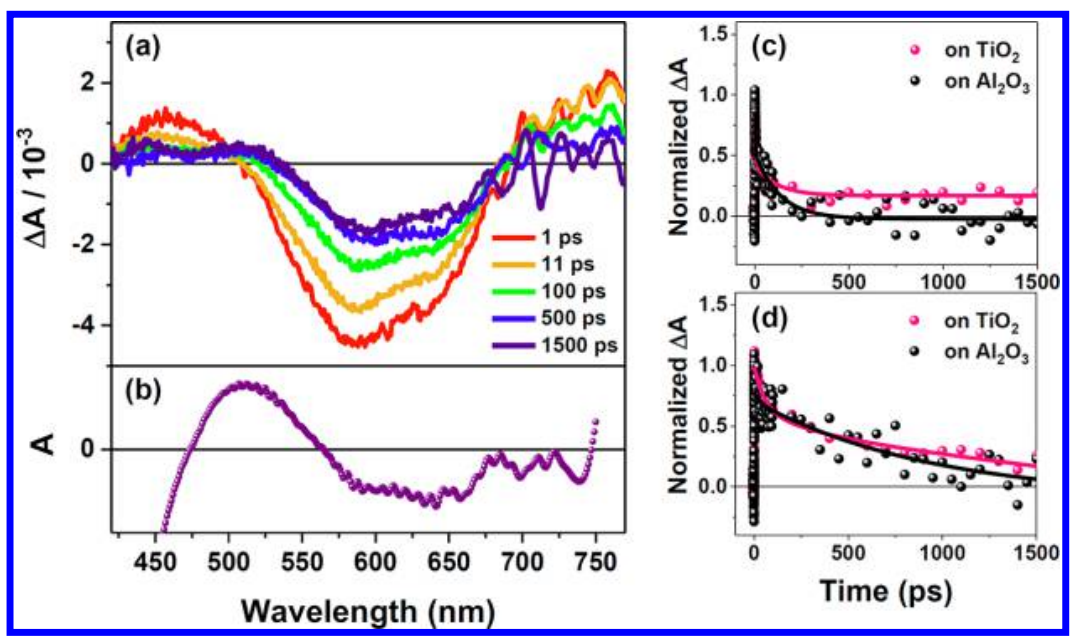

Figure 3. (a) Fs-TA spectra of DPP A on a $\mathrm{TiO}_{2}$ film at different optical delays. The film was prepared by dipping the substrate in a dye bath with a 1:50 dye-to-CDCA ratio and excited at $390 \mathrm{~nm}$ with $28 \mu \mathrm{J} / \mathrm{cm}^{2}$. (b) First derivative spectrum of the steady-state absorption is displayed below part a . fs-TA decay profiles of DPP_A on $\mathrm{Al}_{2} \mathrm{O}_{3}$ and $\mathrm{TiO}_{2}$ films at $470 \mathrm{~nm}$ (c) and $760 \mathrm{~nm}(\mathrm{~d})$ are shown on the right, and all the profiles are normalized to the maximum intensity.

Table 2. TA Decay Parameters and Time Constants $\left(\tau_{i}\right)$ with Their Fractional Amplitudes $\left(A_{i}\right)$ for DPP_A and DPP_R on Mesoporous $\mathrm{Al}_{2} \mathrm{O}_{3}$ and $\mathrm{TiO}_{2}$ Films ${ }^{a}$

\begin{tabular}{|c|c|c|c|c|c|c|}
\hline & & wavelength (nm) & $\tau_{1} / A_{1}(\mathrm{ps} / \%)$ & $\tau_{2} / A_{2}(\mathrm{ps} / \%)$ & $\tau_{3} / A_{3}(\mathrm{ps} / \%)$ & $\tau_{4} / A_{4}(\mathrm{ps} / \%)$ \\
\hline \multirow[t]{6}{*}{ DPP_A } & \multirow[t]{2}{*}{ on $\mathrm{Al}_{2} \mathrm{O}_{3}$} & 470 & $2 / 50$ & $130 / 50$ & & \\
\hline & & 760 & $28 / 92$ & $950 / 8$ & & \\
\hline & \multirow{4}{*}{ on $\mathrm{TiO}_{2}$} & 470 & $4.2 / 22.6$ & $110 / 16.0$ & $>1.5 \mathrm{~ns} / 61.4$ & \\
\hline & & 760 & $52 / 14.4$ & $351 / 29.3$ & $>1.5 \mathrm{~ns} / 56.3$ & \\
\hline & & 705 & 2.8 (rise) & $11 / 0.2$ & $300 / 0.1$ & $>1.5 \mathrm{~ns} / 99.7$ \\
\hline & & $705(1: 0)^{a}$ & 1.0 (rise) & $20 / 5.7$ & $277 / 1.3$ & $>1.5 \mathrm{~ns} / 93.0$ \\
\hline \multirow[t]{6}{*}{ DPP_R } & \multirow[t]{2}{*}{ on $\mathrm{Al}_{2} \mathrm{O}_{3}$} & 680 & 10 (rise) & $460 / 87$ & $1120 / 13$ & \\
\hline & & 750 & 6.0 (rise) & $496 / 88$ & $1200 / 12$ & \\
\hline & \multirow[t]{4}{*}{ on $\mathrm{TiO}_{2}$} & 680 & $5.3 / 25$ (rise) & $340 / 75$ (rise) & $727 / 6.7$ & $>1.5 \mathrm{~ns} / 93.3$ \\
\hline & & 750 & 350 (rise) & $25 / 3$ & $>1.5 \mathrm{~ns} / 97$ & \\
\hline & & 630 & 10 (rise) & $1210 / 43.3$ & $>1.5 \mathrm{~ns} / 56.7$ & \\
\hline & & $630(1: 0)^{\mathrm{a}}$ & 7 (rise) & $11 / 7.6$ & $>1.5 \mathrm{~ns} / 92.4$ & \\
\hline
\end{tabular}

${ }^{a}$ The films were prepared by dipping the substrate in a dye bath without CDCA.

on the $\mathrm{TiO}_{2}$ film show a long-lived species lasting more than 1.5 ns. The detailed fitted parameters are listed in Table 2.

On the basis of the reported time scales of oxidized organic dyes without electrolyte, which range from microseconds to milliseconds, ${ }^{23,26}$ this long-lived feature can be ascribed to the oxidized species produced after electron injection. The ultrafast electron injection process $(<150 \mathrm{fs})$ is again revealed by the absence of rising components in the kinetics, in accordance with the redshift in the GSB band observed at early times. The excitation wavelength of $390 \mathrm{~nm}$ was carefully selected such that the charge injection mechanism could be directly scrutinized by comparing the measurement results with those from previous lateral interaction studies and so that $\mathrm{TiO}_{2}$ absorbance was insignificant. Furthermore, to confirm that no reaction occurs between the photoinduced carriers produced by the $\mathrm{TiO}_{2}$ substrate itself and the dye, an experiment (Supporting Information) was conducted with DPP_A by using a $600 \mathrm{~nm}$ excitation source; at this wavelength, $\mathrm{TiO}_{2}$ absorbance is negligible, and DPP_A shows strong absorption (Supporting Information, Figure $\overline{\text { S2 }}$ and Table S1). On the basis of the similarity in the photodynamics obtained from excitation at 390 and $600 \mathrm{~nm}$, we confirm the absence of any extra reactions.
For the kinetic profile of DPP A on the $\mathrm{TiO}_{2}$ film obtained at $470 \mathrm{~nm}$, the decay components observed before reaching the ns time constant, i.e., 4.2 and 110 ps, can be explained by the occurrence of the transient Stark effect caused by the formation of a local electric field by the photogenerated charge carriers and charge transfer states, as this electric field strongly affects the electronic transitions of the surrounding molecules. ${ }^{27,28}$

This Stark effect also appears in the TA spectra as a gradual redshift with time, and, as displayed in Figure $3 \mathrm{~b}$, the shifted spectra resemble the first derivative spectrum of the steadystate absorption. Dye molecules with a regular alignment on a flat film are known to generate an electric field parallel to the dye upon photoexcitation, resulting in a match between the differential absorption spectrum and the derivative spectrum. ${ }^{29}$ The observation of an almost perfect match between the two spectra suggests that the DPP_A dye molecules are regularly aligned on the $\mathrm{TiO}_{2}$ surface. This alignment is assisted by the charge transfer excitons generated within the triphenylamine donor and neighboring DPP core. ${ }^{30}$ Additionally, the recombination of a fraction of the oxidized species with some of the injected electrons can contribute to the observed spectral decay. 


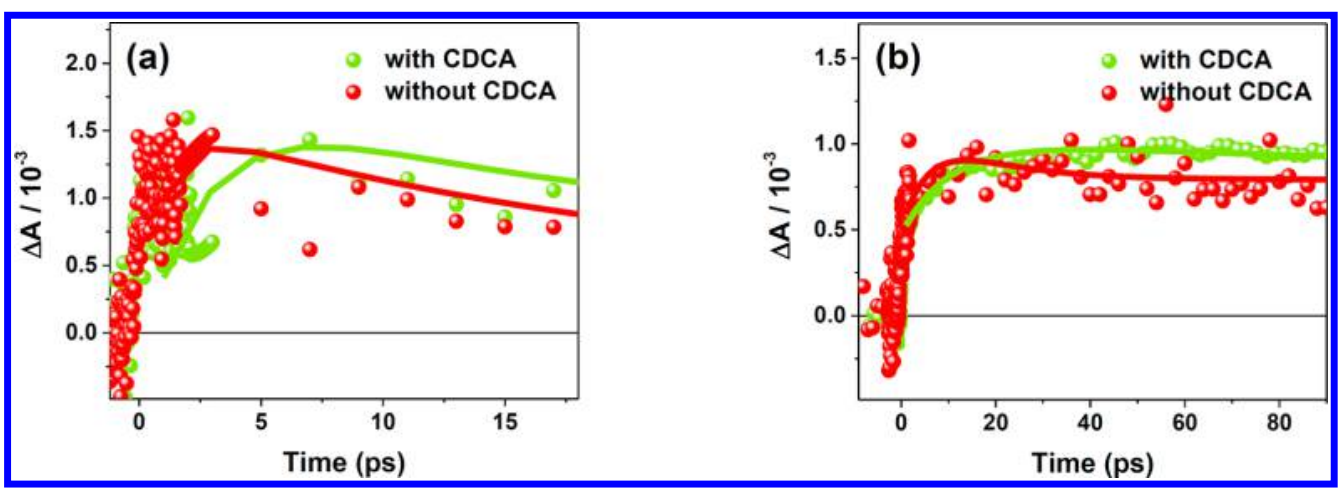

Figure 4. fs-TA decay profiles of DPP_A (a) and DPP_R (b) on $\mathrm{TiO}_{2}$ films measured at 705 and $630 \mathrm{~nm}$, respectively. The films were prepared by dipping substrates into two different dye baths; one bath contained the coadsorbent, CDCA, with a 1:50 ratio of dye to CDCA (green), and the other bath did not contain coadsorbent (red). Both dyes were excited at $390 \mathrm{~nm}$ with $28 \mu \mathrm{J} / \mathrm{cm}^{2}$. All the profiles are normalized to the maximum intensity.

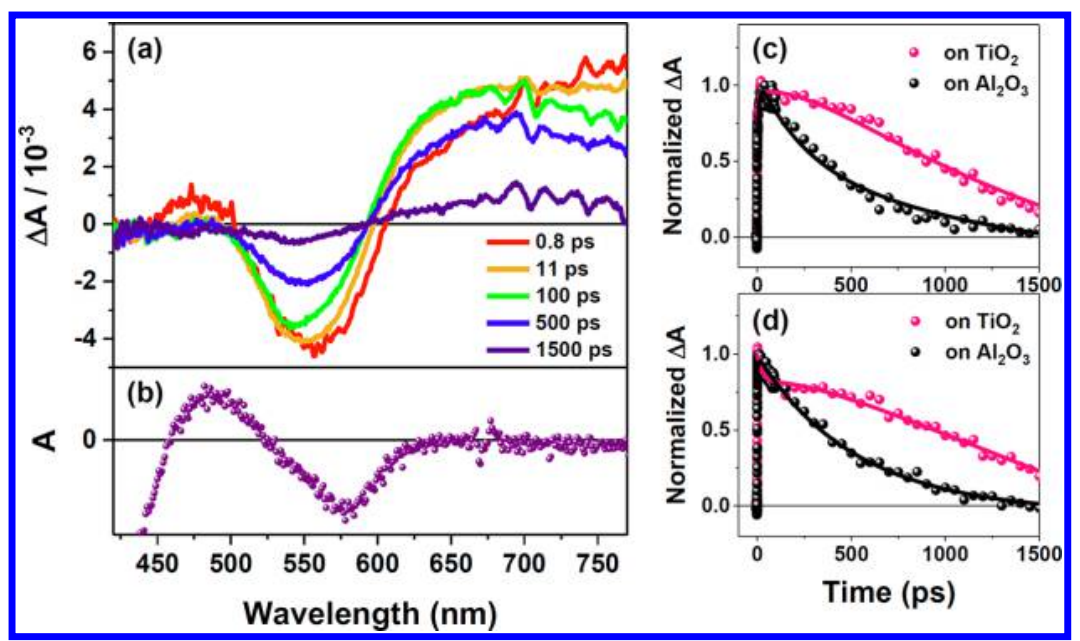

Figure 5. (a) Fs-TA spectra of DPP R on a $\mathrm{TiO}_{2}$ film at different optical delays. The film was prepared by dipping the substrate in a dye bath with a 1:50 dye-to-CDCA ratio and excited at $390 \mathrm{~nm}$ with $28 \mu \mathrm{J} / \mathrm{cm}^{2}$. (b) First derivative spectrum of the steady-state absorption is displayed below part a . The fs-TA decay profiles of $\mathbf{D P P} \_\mathbf{R}$ on $\mathrm{Al}_{2} \mathrm{O}_{3}$ and $\mathrm{TiO}_{2}$ films at $680 \mathrm{~nm}$ (c) and $750 \mathrm{~nm}$ (d) are shown on the right, and all the profiles are normalized to the maximum intensity.

The fact that the red-side ESA band is observed in only the TA spectrum and not in the first derivative absorption spectrum indicates that absorption by the oxidized DPP A species is responsible for the band. ${ }^{23}$ Moreover, this band is also known to overlap with that corresponding to the lateral intermolecular interactions between DPP A dye molecules on the surface. ${ }^{16}$ In a previous study that was performed with an inert $\mathrm{Al}_{2} \mathrm{O}_{3}$ substrate instead of $\mathrm{TiO}_{2}$ to avoid interfacial electron injection, the red-side ESA band, which is sensitive to the loaded dye concentration, was revealed to represent a charge-separated state (CSS) formed by the oxidized and reduced dye molecules produced from lateral intermolecular interactions. Indeed, the formation time of the CSS, observed as a rising component in the kinetic profile of the band, becomes faster when the intermolecular distance becomes shorter. $^{16,31}$

Similar to the results of the previous study on the CSS, as shown in Figure 4 (a), a clear rising component of 2.8 ps is observed at $705 \mathrm{~nm}$ for the film that was fabricated by dipping the substrate into a solution that contained the coadsorbent, CDCA, with a dye-to-CDCA molar fraction of 1:50. This component becomes as fast as 1 ps when CDCA is excluded from the dye bath since the absence of CDCA reduces the intermolecular distance between the loaded dye molecules.
These observations nicely match with those of the previous study, demonstrating the existence of lateral interactions between the remaining neutral dye molecules, even on the $\mathrm{TiO}_{2}$ film.

Compared to the rising component of 18 ps reported for the dye-sensitized $\mathrm{Al}_{2} \mathrm{O}_{3}$ film prepared by adding a coadsorbent, ${ }^{16}$ the rising component of the corresponding $\mathrm{TiO}_{2}$ film prepared under the same condition appears to be faster. The reason for this difference is that the dye concentration on $\mathrm{TiO}_{2}$ is $25 \%$ higher than that on $\mathrm{Al}_{2} \mathrm{O}_{3}$. Thus, the lateral interactions between dye molecules adsorbed on the two oxide surfaces occur on the same time scale. On the basis of the interfacial charge recombination dynamics, deactivation of the CSS formed from the intermolecular interactions is also observed in the kinetic profile obtained at $760 \mathrm{~nm}$, and the average decay component of this process is 110 ps. The existence of intermolecular interactions is evident when considering the fact that a similar average decay component of $102 \mathrm{ps}$ is observed for the dye on $\mathrm{Al}_{2} \mathrm{O}_{3}$.

The clear isosbestic point formed between the GSB and redside ESA bands provides additional evidence for the presence of lateral intermolecular interactions between the regularly aligned DPP_A dye molecules adsorbed on the film. Interestingly, a clear isosbestic point does not appear between 
the GSB and blue-side ESA bands. Instead, a gradual redshift reflecting the Stark effect is observed. The reason for this difference and for why the Stark effect is not observed in the red-side ESA band is the superposition of this band with a spectral blueshift arising from intermolecular interactions between partially delocalized excitons. ${ }^{16}$ In other words, the clear isosbestic point is a response to the Stark effect being screened out, demonstrating the existence of intermolecular interactions.

Photophysical Dynamics of DPP_R on $\mathrm{TiO}_{2}$ Films. Next, the donor-absent DPP_R dye adsorbed on $\mathrm{TiO}_{2}$ films was investigated by fs-TA. Figure 5 a shows the spectra at different optical delays. Compared to the steady-state absorption spectrum, the GSB band is red-shifted by $33 \mathrm{~nm}$ at early times, suggesting that interfacial electron injection occurs within the time resolution of the TA Instruments, as is the case for DPP A. The ESA band above $600 \mathrm{~nm}$ can be assigned to the oxidized DPP_R species based on comparison of the TA kinetic profiles of the dye on $\mathrm{Al}_{2} \mathrm{O}_{3}$ and $\mathrm{TiO}_{2}$. As shown in parts $\mathrm{c}$ and $\mathrm{d}$ of Figure 5, in contrast to the dye on $\mathrm{Al}_{2} \mathrm{O}_{3}$, longlived species lasting more than $1.5 \mathrm{~ns}$ are observed at 680 and $750 \mathrm{~nm}$, suggesting the formation of oxidized species as a result of electron injection.

In addition to the long-lived decay component, slow rising components of $340 \mathrm{ps}$ at $680 \mathrm{~nm}$ and $350 \mathrm{ps}$ at $750 \mathrm{~nm}$ also emerge in the profile of the DPP_R dye on $\mathrm{TiO}_{2}$; these components are not observed for the dye adsorbed to $\mathrm{Al}_{2} \mathrm{O}_{3}$. This difference may originate from delayed electron transfer from some of the remaining neutral DPP_R dye molecules in the singlet excited state $\left(S_{1}\right)$. This premise is supported by the observation of a gradual redshift in the spectra beyond a $100 \mathrm{ps}$ optical delay (Supporting Information, Figure S3), where the redshift indicates that the Stark effect originates from the local electric field generated by delayed electron transfer. This redshift is not observed before 100 ps.

The biphasic electron transfer process containing delayed components can be explained by the reduced ICT character of the donor-absent DPP_R dye, which can also be responsible for the decreased solar cell efficiency of this compound. Indeed, while the reported PCE of DPP_A in iodide electrolyte is $7.60 \%,{ }^{10}$ the measured PCE of DPP_R is reduced to $3.23 \%$, as described in Supporting Information, Figure S4.

Interestingly, the Stark effect, observed as a gradual redshift in the TA spectra of DPP_R, is not clearly observed after the fast electron injection process but is observed after the slower second electron injection component. This difference can be explained by the fact that the fast injection of DPP_R is not efficient enough to induce the Stark effect.

One of the explanations for the occurrence of delayed electron transfer is the planar geometry of the DPP_R dye molecules, which easily facilitates excimer-like excited-state formation through $\pi-\pi$ interactions upon photoexcitation, ${ }^{32,33}$ This excited state acts as a trap state for charges or excitons. $^{34-36}$ Additionally, the excimer-like excited state lowers the energy level, ${ }^{37,38}$ thereby decreasing the driving force for electron injection.

In more detail, the fast rising component of 5.3 ps that appears at $680 \mathrm{~nm}$ is ascribed to lateral intermolecular interactions based on comparison of the kinetic profiles for the $\mathrm{TiO}_{2}$ and $\mathrm{Al}_{2} \mathrm{O}_{3}$ films, which show similar rising components. As further evidence, Figure $5 \mathrm{~b}$ exhibits the occurrence of faster rising components with increased dye concentration on $\mathrm{TiO}_{2}$ at $630 \mathrm{~nm}$, where lateral intermolecular interactions are clearly observed. ${ }^{16}$ For the kinetic profile measured at $750 \mathrm{~nm}$, the appearance of a $25 \mathrm{ps}$ decay component before the delayed electron transfer instead of a fast rising feature can be explained by the relaxation of the DPP_R dye molecules in the $S_{1}$ state since $750 \mathrm{~nm}$ is far from the region at which lateral intermolecular interactions are strongly observed $(c a .630 \mathrm{~nm}){ }^{16}$ The fact that excited-state relaxation of the neutral DPP $\mathbf{R}$ dye molecules on $\mathrm{TiO}_{2}$ is detected suggests that electron injection from the DPP_R dye to $\mathrm{TiO}_{2}$ occurs inefficiently, leaving dye molecules in a neutral excited state upon photoexcitation.

These kinetic characteristics of the DPP $\mathbf{R}$ film are also observed in the profiles obtained by using a $530 \mathrm{~nm}$ light source; at this wavelength, $\mathrm{TiO}_{2}$ does not absorb, whereas DPP_R absorption is maximized (Supporting Information, Figure S2 and Table S1). The only difference is in the rate of intermolecular interaction formation, which is recognized as the rising kinetic components in the profile probed at $630 \mathrm{~nm}$. Under low-energy excitation at $530 \mathrm{~nm}$, intermolecular interactions occur three times slower than under excitation at $390 \mathrm{~nm}$. The origin of the slow intermolecular interaction lies in the stability of the CSS that results from the interactions on the DPP_R film. The low stability of the oxidized and reduced DPP_R dye molecules caused by the decreased ICT characteristic leads to a high-energy CSS, thereby reducing the gap between the molecular excited state and the CSS. As a result, the driving force for lateral interaction between DPP_R dye molecule becomes weak, and when the pump energy is not strong enough, unlike in the case of the $390 \mathrm{~nm}$ exciton source, CSS formation becomes slower. Interestingly, this pump energy dependence of the lateral interaction dynamics is not clearly observed in the case of DPP_A, which has strong ICT characteristics. This difference again demonstrates the effect of the ICT characteristics of a dye on CSS formation.

The noticeable difference observed in the kinetic results for the DPP_A and DPP_R films is due to differences in the relative intermolecular interaction rates compared to the respective charge injection rates. In the case of DPP_A, the interfacial injection process is much faster than the interaction between dye molecules, while DPP_R still shows slow secondary injection after the formation of intermolecular interactions.

This difference clearly indicates that the electron donor moiety is important for achieving an efficient dye sensitizer. The donor prevents interfacial charge injection processes from being intercepted by other processes, such as intermolecular interactions, by accelerating the injection rate.

Fluence-Dependent Dynamics of DPP_A and DPP_R on $\mathrm{TiO}_{2}$ Films. It is well established that the recombination rate is strongly dependent on the external bias such as the light intensity, which varies the electron concentrations in the conduction band and in the trap states of mesoporous $\mathrm{TiO}_{2}{ }^{39-41}$ The effect of the pump fluence on the charge recombination process between oxidized dye molecules and electrons in the conduction band of $\mathrm{TiO}_{2}$ was investigated in DPP_A and DPP_R films by examining different excitation fluences.

According to the pump fluence, the average number of electron/oxidized dye $\left(\mathrm{e}_{c b}^{-} / S^{+}\right)$pairs generated per illuminated spherical nanoparticle in a film can be derived from the following equation: ${ }^{39}$ 


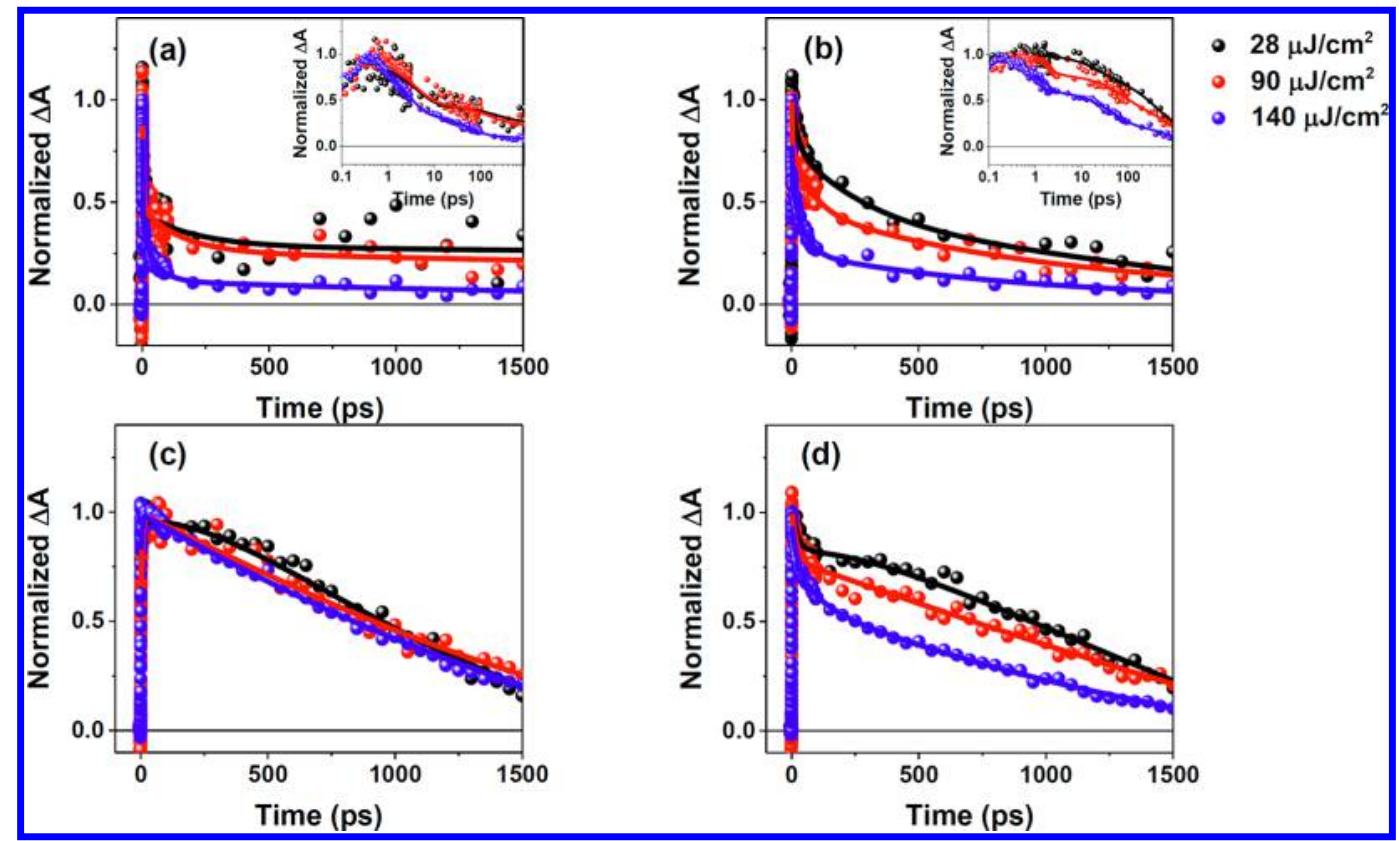

Figure 6. fs-TA decay profiles of DPP A on a $\mathrm{TiO}_{2}$ film at $440 \mathrm{~nm}$ (a) and $760 \mathrm{~nm}$ (b) and of the corresponding DPP R film at $680 \mathrm{~nm}$ (c) and $750 \mathrm{~nm}(\mathrm{~d})$. The films were prepared by dipping the substrate in a dye bath with a 1:50 dye-to-CDCA ratio and excited at $390 \mathrm{~nm}$ with 28,90 , and $140 \mu \mathrm{J} / \mathrm{cm}^{2}$. All the profiles are normalized to the maximum intensity.

Table 3. TA Decay Parameters and Time Constants $\left(\tau_{i}\right)$ with Their Fractional Amplitudes $\left(A_{i}\right)$ for DPP A and DPP R on Mesoporous $\mathrm{Al}_{2} \mathrm{O}_{3}$ and $\mathrm{TiO}_{2}$ Films

\begin{tabular}{|c|c|c|c|c|c|c|}
\hline & wavelength $(\mathrm{nm})$ & fluence $\left(\mu \mathrm{J} / \mathrm{cm}^{2}\right)$ & $\tau_{1} / A_{1}(\mathrm{ps} / \%)$ & $\tau_{2} / A_{2}(\mathrm{ps} / \%)$ & $\tau_{3} / A_{3}(\mathrm{ps} / \%)$ & $\tau_{4} / A_{4}(\mathrm{ps} / \%)$ \\
\hline \multirow[t]{6}{*}{$\mathrm{DPP}_{-} \mathrm{A}$} & 440 & 28 & $3.9 / 26.5$ & $212 / 8.8$ & $>1.5 \mathrm{~ns} / 64.7$ & \\
\hline & & 90 & $3.7 / 50.7$ & $152 / 20.5$ & $>1.5 \mathrm{~ns} / 28.8$ & \\
\hline & & 140 & $2.2 / 67.2$ & $53 / 23.6$ & $>1.5 \mathrm{~ns} / 9.2$ & \\
\hline & 760 & 28 & $52 / 14.4$ & $351 / 29.3$ & $>1.5 \mathrm{~ns} / 56.3$ & \\
\hline & & 90 & $0.9 / 37$ & $76 / 23$ & $>1.5 \mathrm{~ns} / 40$ & \\
\hline & & 140 & $0.6 / 53$ & $44 / 22$ & $900 / 31$ & \\
\hline \multirow[t]{6}{*}{ DPP_R } & 680 & 28 & $5.3 / 25$ (rise) & $340 / 75$ (rise) & $727 / 6.7$ & $>1.5 \mathrm{~ns} / 93.3$ \\
\hline & & 90 & $6 / 88$ (rise) & $340 / 12$ (rise) & $>1.5 \mathrm{~ns}$ & \\
\hline & & 140 & $5.1 />99.8$ (rise) & $340 /<0.02$ (rise) & $>1.5 \mathrm{~ns}$ & \\
\hline & 750 & 28 & 350 (rise) & $25 / 3$ & $>1.5 \mathrm{~ns} / 97$ & \\
\hline & & 90 & 340 (rise) & $20 / 6.8$ & $>1.5 \mathrm{~ns} / 93.2$ & \\
\hline & & 140 & $19.5 / 12.3$ & $88 / 15.2$ & $>1.5 \mathrm{~ns} / 72.5$ & \\
\hline
\end{tabular}

$$
\langle x\rangle=\frac{\lambda_{e x} \cdot F_{e x} \cdot\left(1-10^{-A}\right) \cdot 4 \pi \cdot r^{3}}{3 h \cdot c \cdot d \cdot \phi}
$$

where $\lambda_{e x}$ is the excitation wavelength, $F_{e x}$ is the energy fluence per laser pulse, $A$ is the absorbance of a dye at $\lambda_{e x}, h$ is the Planck constant, $c$ is the speed of light, $r$ is the average nanoparticle radius, $d$ is the thickness of the mesoporous film, and $\varphi$ is the film porosity.

Considering the experimental conditions of both films, when the pump fluence changes from 28 to $140 \mu \mathrm{J} / \mathrm{cm}^{2}$, the $\langle x\rangle$ value increases from 0.52 to 1.67 and 2.60 for the DPP_A film and from 0.57 to 1.83 and 2.85 for the DPP_R film.

As presented in parts $a$ and $b$ of Figure 6 and Table 3, the decay time constants of DPP_A at 440 and $760 \mathrm{~nm}$ become faster as the pump fluence changes from 28 to $140 \mu \mathrm{J} / \mathrm{cm}^{2}$, decreasing the portion of the ns component. This trend reflects accelerated $\mathrm{TiO}_{2}$ electron-oxidized dye recombination due to the high free electron density and the high concentration of oxidized states per nanoparticle, which is caused by enhanced excitation photon density. In the recombination model derived for colloidal $\mathrm{TiO}_{2}$ particles, ${ }^{42}$ this acceleration is explained by the recombination of free electrons with trapped holes at the surface of particles under high fluence, which corresponds perfectly to our case here, where holes are replaced by oxidized species.

More supporting evidence is shown in parts $c$ and $d$ of Figure 6, where the fluence-dependent dynamics of DPP_R dye measured at 680 and $750 \mathrm{~nm}$, respectively, show a decrease in the average decay time constant with increasing pump fluence. Note that the delayed electron transfer of the DPP_R dye gradually decreases as the pump fluence increases, suggesting that overall electron transfer becomes fast under a high excitation photon density. As the pump fluence increases, the TA spectra at an early time of 0.8 ps display the growth of the red-side ESA band corresponding to the oxidized DPP_R species as a result of electron injection (Supporting Information, Figure S5). These observations are indeed in line with the argument that the electron-oxidized dye recombination process is accelerated by a high pump fluence. 


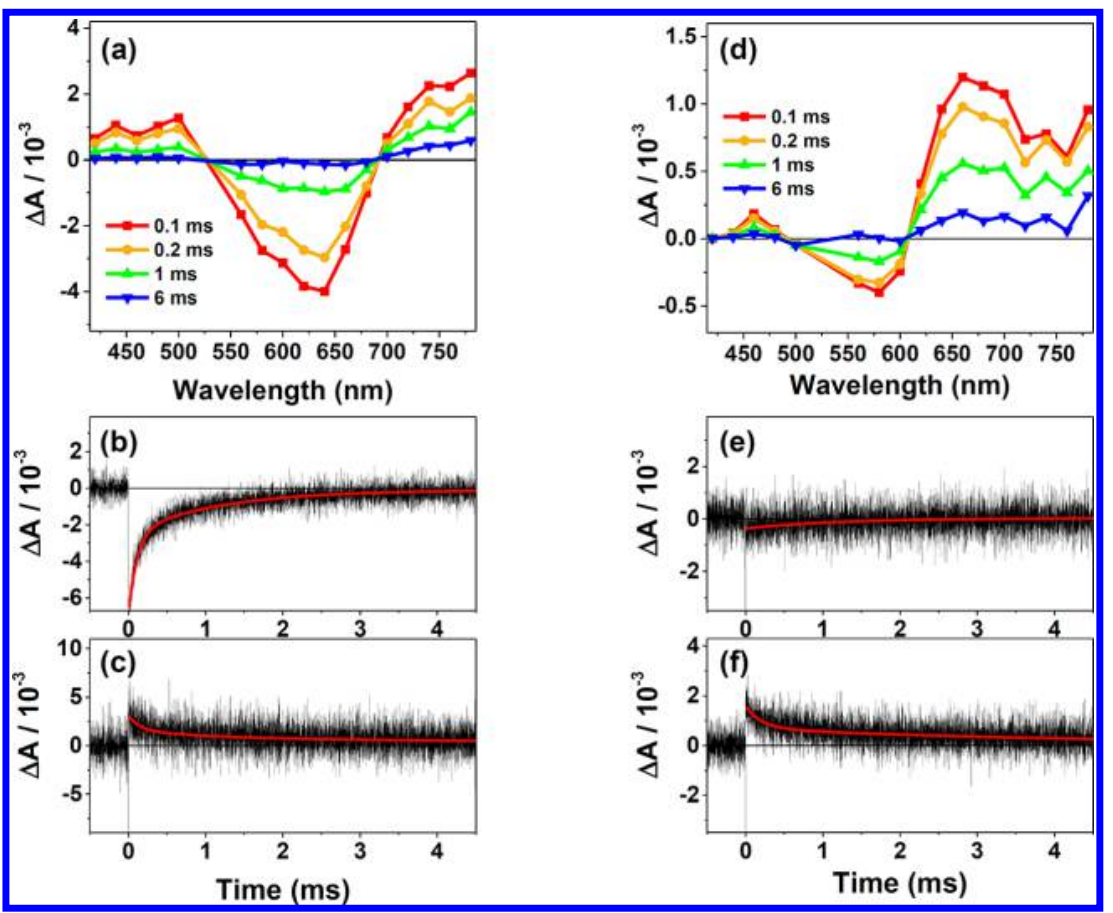

Figure 7.ns-TA spectra of DPP_A (a) and DPP_R (d) on $\mathrm{TiO}_{2}$ films measured at different optical delays and normalized to the absorption value at the excitation wavelength, $532 \mathrm{~nm}$. The spectra were constructed by integrating the kinetic profiles every $20 \mathrm{~nm}$ from 420 to $780 \mathrm{~nm}$. The films were prepared by dipping the substrate in a dye bath with a 1:50 dye-to-CDCA ratio and excited at $532 \mathrm{~nm}$ with less than $30 \mu \mathrm{J} / \mathrm{cm}^{2}$. The representative kinetic profiles of DPP_A at 640 (b) and $740 \mathrm{~nm}$ (c) and DPP_R at 560 (e) and $660 \mathrm{~nm}$ (f) are shown below the spectra.

Table 4. ns-TA Decay Parameters and Time Constants $\left(\tau_{i}\right)$ with their fractional amplitudes $\left(A_{i}\right)$ for DPP_A and DPP_R on mesoporous $\mathrm{TiO}_{2}$ films with 1:50 and 1:0 dye-to-CDCA ratios

\begin{tabular}{|c|c|c|c|c|c|c|}
\hline & & wavelength $(\mathrm{nm})$ & $\tau_{1} / A_{1}(\mu \mathrm{s} / \%)$ & $\tau_{2} / A_{2}(\mu \mathrm{s} / \%)$ & $\tau_{3} / A_{3}(\mu \mathrm{s} / \%)$ & $\tau_{\text {ave }}(\mu \mathrm{s})$ \\
\hline \multirow[t]{4}{*}{ with CDCA } & DPP_A & 640 & $64 / 36$ & $440 / 50$ & $4230 / 14$ & 835 \\
\hline & & 740 & $118 / 47$ & $746 / 27$ & $5320 / 26$ & 1640 \\
\hline & DPP_R & 560 & $40 / 31$ & $1210 / 69$ & - & 847 \\
\hline & & 660 & $200 / 58$ & $4300 / 42$ & - & 1922 \\
\hline \multirow[t]{4}{*}{ without CDCA } & DPP_A & 640 & $92 / 71$ & $1480 / 29$ & - & 495 \\
\hline & & 740 & $298 / 67$ & $4200 / 33$ & - & 1586 \\
\hline & DPP_R & 560 & $132 / 69$ & $1510 / 31$ & - & 559 \\
\hline & & 660 & $234 / 76$ & $4420 / 24$ & - & 1238 \\
\hline
\end{tabular}

3.3. Flash Photolysis Measurements. Flash photolysis measurements were conducted to investigate the long-time scale back electron transfer dynamics by using a $532 \mathrm{~nm}$ excitation source. The pump fluence was controlled to be less than $35 \mu \mathrm{J} / \mathrm{cm}^{2}$, at which an average of less than one electron can be injected into $\mathrm{TiO}_{2}$, to avoid the excitation intensitydependent back electron transfer that appears at pump fluence values higher than this threshold. ${ }^{41}$ The TA spectra shown in Figure 7 , which were constructed by integrating the kinetic profiles every $20 \mathrm{~nm}$ from 420 to $780 \mathrm{~nm}$, show the microsecond to millisecond photophysical behaviors of the DPP_A and DPP_R dye films.

Although the spectral characteristics shown in parts and $d$ of Figure 7 are similar to those measured by fs-TA, the spectra obtained by flash photolysis show only decay components across the spectral range with clear isosbestic points. This result shows that the charge recombination process occurs in the microsecond-to-millisecond regime.

Parts $b$ and $c$ and parts $e$ and $f$ of Figure 7 show the representative kinetic profiles of $\mathbf{D P P} \mathbf{A}_{\mathbf{A}}$ and $\mathbf{D P P} \mathbf{R}$, respectively. As listed in Table 4, a multiexponential decay characteristic is observed in both cases, and this characteristic is also found in other dye-sensitized solar cells. ${ }^{23,43}$ This multiexponential decay characteristic can be caused by the trapping of conduction band electrons in a range of energy levels or by the various geometrical dye configurations adopted by the oxidized dye molecules adsorbed on the surface. The dye configuration parameters, such as the tilting angle, which controls the distance from the surface to the radical cation site on the molecule, can induce multiexponential electron transfer kinetics.

As shown in Table 4, the recombination rates are independent of the presence of the donor moiety. The molecular configuration on the $\mathrm{TiO}_{2}$ surface can be considered as a rationale for the observation of similar kinetic behaviors. The complex molecular structure of DPP_A, unlike that of DPP_R, does not guarantee an aligned geometry on the surface, maximizing the distance between the highest occupied molecular orbital (HOMO) of the dye and the electrons in the nanoparticle. Thus, distorted geometries such as a slanted configuration can reduce the distance between the reaction sites and affect the recombination time of DPP_A. 


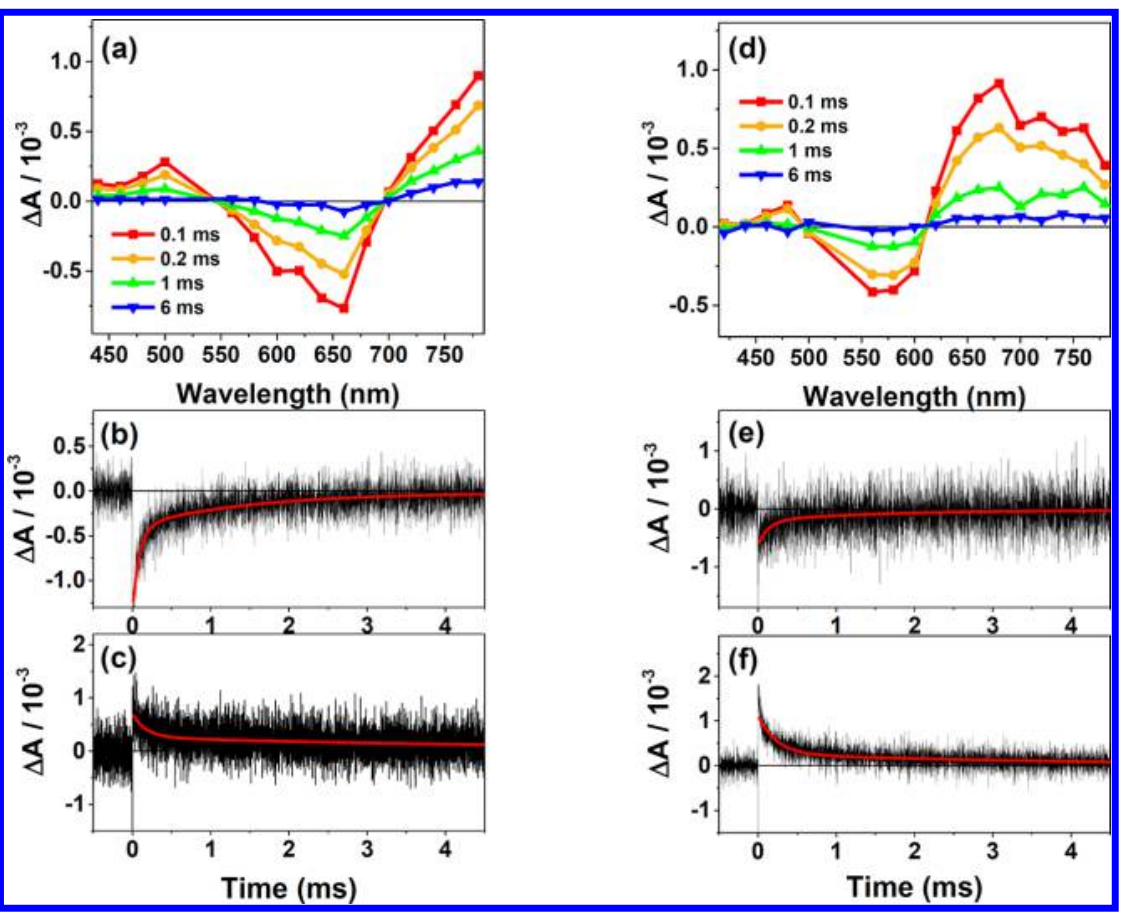

Figure 8. ns-TA spectra of DPP_A (a) and DPP_R (d) on $\mathrm{TiO}_{2}$ films measured at different optical delays and normalized to the absorption values at the excitation wavelength of $\bar{\lambda}=532 \mathrm{~nm}$. The films were prepared by dipping the substrate in a dye bath with a 1:0 dye-to-CDCA ratio and excited at $532 \mathrm{~nm}$ with less than $30 \mu \mathrm{J} / \mathrm{cm}^{2}$. The representative kinetic profiles of DPP_A at 640 (b) and $740 \mathrm{~nm}$ (c) and of DPP_R at 560 (d) and $660 \mathrm{~nm}(\mathrm{f})$ are shown below the spectra.

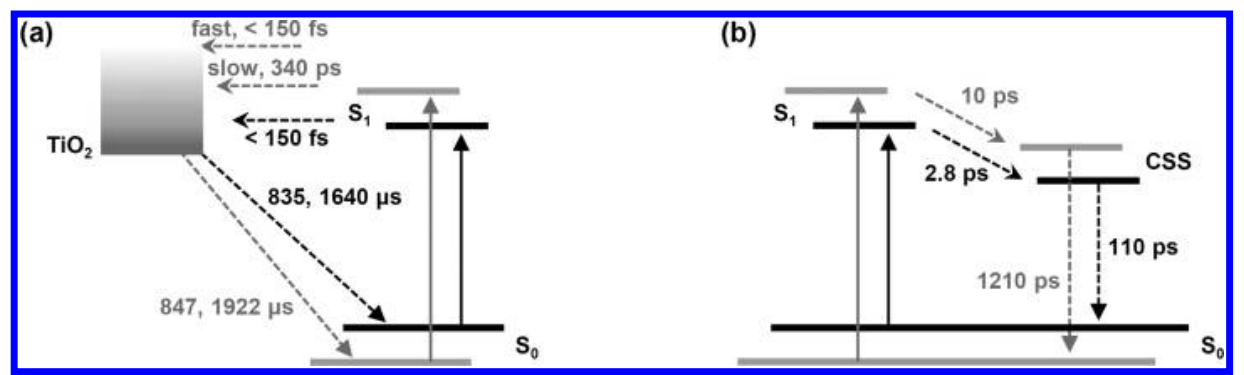

Figure 9. Kinetic processes of DPP_A (black) and DPP_R (gray) adsorbed on $\mathrm{TiO}_{2}$ with a 1:50 dye-to-CDCA ratio upon photoexcitation at 390 $\mathrm{nm}$. The electron transfer mechanism (a) and energy diagram of the lateral intermolecular interactions (b) are illustrated.

Even though the electron donor does not have a large influence on the recombination kinetics, it is remarkable that the regions at which lateral intermolecular interactions are observed (above 700 and $610 \mathrm{~nm}$ for DPP_A and DPP_R, respectively) exhibit slower recombination times than other wavelength ranges for both dyes.

The increased recombination time observed in the intermolecular interaction-sensitive region is probably due to a screening effect of the remaining reduced dye species formed from the intermolecular interactions on the electron-cation recombination process. Regarding the reduced dye species, the interaction between loaded organic dye molecules upon photoexcitation simultaneously generates oxidized and reduced dye species on the inert $\mathrm{Al}_{2} \mathrm{O}_{3}$ surface. ${ }^{31}$ Considering that lateral intermolecular interactions also exist on the $\mathrm{TiO}_{2}$ film, it is not surprising that the remaining reduced species located near the oxidized ones can repel the injected electron, thereby retarding the recombination process.

Additionally, the formation of strong intermolecular interactions at the surface facilitated by particular molecular tilting angles can confine the electron transfer distance, leading to a different recombination rate. To clarify the effect of the lateral intermolecular interactions on charge recombination, flash photolysis was conducted on films derivatized with only the dye, i.e., without CDCA. The spectra and kinetics of these films are displayed in Figure 8.

The CDCA-containing DPP_A film shows a 2.0 times slower average recombination time, $\tau_{\text {ave }}$ at $740 \mathrm{~nm}$ than at 640 $\mathrm{nm}$. In the case of the film without CDCA, which is expected to exhibit stronger intermolecular interactions, the proportion increases to 3.2 , as listed in Table 4. The enhanced recombination time in the more concentrated dye film suggests that the presence of more reduced species prevents electroncation recombination by screening the oxidized species. On the other hand, the DPP $\mathbf{R}$ film shows a consistent recombination time increase of 2.2-fold regardless of the loaded dye concentration when comparing $\tau_{\text {ave }}$ at 660 and $560 \mathrm{~nm}$. This result agrees with that of the previous study in which the intermolecular interactions reach saturation in the CDCAcontaining film. ${ }^{16}$

In highly concentrated DPP_A and DPP_R films without CDCA, other characteristics, such as an overall accelerated 
charge recombination time, which is an indication of inefficient electron injection when the coadsorbent is absent, are observed. CDCA is used to enhance the organic dye-sensitized solar cell efficiency by negatively shifting the band edge of $\mathrm{TiO}_{2}$ to increase the electron lifetime in $\mathrm{TiO}_{2}$ nanoparticles, leading to reduced recombination of the electrons. ${ }^{18,44-46}$ The effect of CDCA is also revealed when we compare the spectral intensities of the respective dyes normalized to the absorbance at $532 \mathrm{~nm}$ in Figure 7 and Figure 8. Although the dye concentrations of the films used in Figure 8 are higher than those used in Figure 7, the overall spectral intensities are lower in Figure 8. This intensity inversion indicates that CDCA allows more dye molecules to participate in the charge transfer dynamics.

The fact that the spectra in Figure 7 normalized to the absorbance at the excitation wavelength of $532 \mathrm{~nm}$ exhibit stronger intensities than those of the much higher concentrated film in Figure 8a provides additional evidence of the retarded recombination of electrons by CDCA.

Figure 9 shows a schematic diagram of the energy relaxation dynamics observed for the DPP_A (black) and DPP_R (gray) films upon photoexcitation. The occurrence of the lateral intermolecular interaction route before delayed electron injection in the DPP_R films is one of the factors that deteriorates the solar cell efficiency of the donor-absent DPP dye.

\section{CONCLUSIONS}

The effect of the donor on the interfacial charge transfer dynamics of push-pull (DPP_A) and donor-absent (DPP_R) DPP dyes on $\mathrm{TiO}_{2}$ films have been investigated by using a combination of steady-state, femtosecond transient absorption (fs-TA) and flash photolysis measurements.

The effect of an electron donor on the photophysical properties of both dyes adsorbed on $\mathrm{TiO}_{2}$ films was first monitored in steady-state experiments. Unlike DPP_R, DPP_A shows a significant spectral redshift due to the occurrence of enhanced intramolecular charge transfer (ICT) arising from the strong electron-donating group. The driving force for interfacial electron injection induced by the strong ICT characteristic is demonstrated by the fs-TA results, suggesting that most of the electrons from DPP_A are injected into the conduction band of $\mathrm{TiO}_{2}$ within the time resolution of TA ( $<150$ fs), while DPP_R displays biphasic electron injection behavior, including a delayed process of $c a .340$ ps.

The influence of the donor on interfacial injection becomes more evident when the lateral intermolecular interactions are also considered. The intermolecular interactions observed on $\mathrm{TiO}_{2}$, which are often ignored since the injection of excited electrons from dyes to $\mathrm{TiO}_{2}$ is normally ultrafast, form chargeseparated states (CSS) in both dye films, thereby deteriorating the interfacial charge transfer dynamics when the electron donor is absent. This deterioration occurs because whereas the relative rate of injection becomes much faster than the rate of CSS formation in DPP_A due to the increased ICT characteristic, DPP_R exhibits an additional delayed injection rate that is slower than the CSS formation rate. This result demonstrates that the presence of an electron donor prevents interception of the injection dynamics by the intermolecular interaction pathway, leading to more efficient injection from DPP A.

Contrary to the injection process, the effect of the donor on charge recombination between an electron and a dye cation is insignificant. Furthermore, we have revealed that lateral dye interactions affect the recombination of electrons with dye cations by delaying the dynamics since the cation is screened from the electrons by some of the remaining reduced species resulting from the intermolecular interactions.

\section{ASSOCIATED CONTENT}

\section{Supporting Information}

The Supporting Information is available free of charge on the ACS Publications website at DOI: 10.1021/acs.jpcc.8b04819.

Additional figures and tables reporting details of steadystate and time-resolved data and photovoltaic efficiency results of DPP_R-sensitized solar cells (PDF)

\section{AUTHOR INFORMATION}

\section{Corresponding Author}

*(J.-E.M.) E-mail: je.moser@epfl.ch. ORCID $\odot$

Jacques-E. Moser: 0000-0003-0747-4666

\section{Notes}

The authors declare no competing financial interest.

\section{ACKNOWLEDGMENTS}

Financial support by the Swiss National Science Foundation (Grant No. 2000021 157135) and NCCR-MUST, a research instrument of the Swiss NSF, is gratefully acknowledged. The authors thank the Technician Training Laboratory of the Institute of Chemical Sciences and Engineering of EPFL, its apprentices and its supervisor, Dr. Luke Harris, for the synthesis of the DPP_R dye.

\section{REFERENCES}

(1) Grätzel, M. Photoelectrochemical Cells. Nature 2001, 414, 338344.

(2) Hagfeldt, A.; Grätzel, M. Molecular Photovoltaics. Acc. Chem. Res. 2000, 33, 269-277.

(3) Mishra, A.; Fischer, M. K. R.; Bäuerle, P. Metal-Free Organic Dyes for Dye-Sensitized Solar Cells: From Structure: Property Relationships to Design Rules. Angew. Chem. Int. Ed. 2009, 48, 2474-2499.

(4) Qu, S.; Wu, W.; Hua, J.; Kong, C.; Long, Y.; Tian, H. New Diketopyrrolopyrrole (DPP) Dyes for Efficient Dye-Sensitized Solar Cells. I. Phvs. Chem. C 2010, 114, 1343-1349.

(5) Yum, J.-H.; Holcombe, T. W.; Kim, Y.; Yoon, J.; Rakstys, K.; Nazeeruddin, M. K.; Grätzel, M. Towards High-Performance DPPBased Sensitizers for DSC Applications. Chem. Commun. 2012, 48, 10727-10729.

(6) Holcombe, T. W.; Yum, J.-H.; Yoon, J.; Gao, P.; Marszalek, M.; Censo, D. D.; Rakstys, K.; Nazeeruddin, M. K.; Grätzel, M. A Structural Study of DPP-Based Sensitizers for DSC Applications. Chem. Commun. 2012, 48, 10724-10726.

(7) Warnan, J.; Favereau, L.; Pellegrin, Y.; Blart, E.; Jacquemin, D.; Odobel, F. A Compact Diketopyrrolopyrrole Dye as Efficient Sensitizer in Titanium Dioxide Dye-Sensitized Solar Cells. L. Photochem. Photobiol. A 2011, 226, 9-15.

(8) Alex, S.; Santhosh, U.; Das, S. Dye Sensitization of Nanocrystalline $\mathrm{TiO}_{2}$ : Enhanced Efficiency of Unsymmetrical Versus Symmetrical Squaraine Dyes. I. Photochem. Photobiol., A 2005, 172, 63-71.

(9) Li, C.; Wang, W.; Wang, X.; Zhang, B.; Cao, Y. Molecular Design of Squaraine Dyes for Efficient Far-Red and Near-IR Sensitization of Solar Cells. Chem. Lett. 2005, 34, 554-555.

(10) Yum, J.-H.; Holcombe, T. W.; Kim, Y.; Rakstys, K.; Moehl, T.; Teuscher, J.; Delcamp, J. H.; Nazeeruddin, M. K.; Grätzel, M. Blue- 
Coloured Highly Efficient Dye-Sensitized Solar Cells by Implementing the Diketopyrrolopyrrole Chromophore. Sci. Rep. 2013, 3, 2446.

(11) Zollinger, H. Color Chemistry: Syntheses, Properties, and Applications of Organic Dyes and Pigments; Wiley: 2003.

(12) Ganesan, P.; Yella, A.; Holcombe, T. W.; Gao, P.; Rajalingam, R.; Al-Muhtaseb, S. A.; Grätzel, M.; Nazeeruddin, M. K. Unravel the Impact of Anchoring Groups on the Photovoltaic Performances of Diketopyrrolopyrrole Sensitizers for Dye-Sensitized Solar Cells. ACS Sustainable Chem. Eng. 2015, 3, 2389-2396.

(13) Qu, S.; Qin, C.; Islam, A.; Hua, J.; Chen, H.; Tian, H.; Han, L. Tuning the Electrical and Optical Properties of Diketopyrrolopyrrole Complexes for Panchromatic Dye-Sensitized Solar Cells. Chem. Asian J. 2012, 7, 2895-2903.

(14) Qu, S.; Tian, H. Diketopyrrolopyrrole (DPP)-Based Materials for Organic Photovoltaics. Chem. Commun. 2012, 48, 3039-3051.

(15) Yang, J.; et al. Influence of the Donor Size in D- $\pi$-A Organic Dyes for Dye-Sensitized Solar Cells. I. Am. Chem. Soc. 2014, 136, 5722-5730.

(16) Bahng, H.-W.; Hagfeldt, A.; Moser, J.-E. Lateral Intermolecular Electronic Interactions of Diketopvrrolopvrrole D- $\pi$-A Solar Dye Sensitizers Adsorbed on Mesoporous Alumina. I. Phys. Chem. C 2018, DOI: 10.1021/acs.jpcc.8b04815.

(17) Zhu, X. Y.; Yang, Q.; Muntwiler, M. Charge-Transfer Excitons at Organic Semiconductor Surfaces and Interfaces. Acc. Chem. Res. 2009, 42, 1779-1787.

(18) Yum, J.-H.; Moon, S.; Humphry-Baker, R.; Walter, P.; Geiger, T.; Nüesch, F.; Grätzel, M.; Nazeeruddin, M. K. Effect of Coadsorbent on the Photovoltaic Performance of Squaraine Sensitized Nanocrystalline Solar Cells. Nanotechnology 2008, 19, 424005.

(19) Blanche, P. A. Photorefractive Organic Materials and Applications: Springer: 2016.

(20) Fakis, M.; Hrobárik, P.; Yushchenko, O.; Sigmundová, I.; Koch, M.; Rosspeintner, A.; Stathatos, E.; Vauthey, E. Excited State and Injection Dynamics of Triphenylamine Sensitizers Containing a Benzothiazole Electron-Accepting Group on $\mathrm{TiO}_{2}$ and $\mathrm{Al}_{2} \mathrm{O}_{3}$ Thin Films. I. Phvs. Chem. C 2014, 118, 28509-28519.

(21) Cherepy, N. J.; Smestad, G. P.; Grätzel, M.; Zhang, J. Z. Ultrafast Electron Injection: Implications for a Photoelectrochemical Cell Utilizing an Anthocyanin Dye-Sensitized $\mathrm{TiO}_{2}$ Nanocrystalline Electrode. I. Phvs. Chem. B 1997, 101, 9342-9351.

(22) Teuscher, J. Dynamics of Electron Transfer Processes at the Surface of Dye-Sensitized Mesoporous Semiconductor Films, Ph.D. Thesis No. 4731. EPFL: Lausanne, Switzerland, 2010.

(23) Oum, K.; Lohse, P. W.; Klein, J. R.; Flender, O.; Scholz, M.; Hagfeldt, A.; Boschloo, G.; Lenzer, T. Photoinduced Ultrafast Dynamics of the Triphenylamine-Based Organic Sensitizer D35 on $\mathrm{TiO}_{2}, \mathrm{ZrO}_{2}$ and in Acetonitrile. Phys. Chem. Chem. Phys. 2013, 15, 3906-3916.

(24) Oum, K.; Lohse, P. W.; Flender, O.; Klein, J. R.; Scholz, M.; Lenzer, T.; Du, J.; Oekermann, T. Ultrafast Dynamics of the Indoline Dye D149 on Electrodeposited $\mathrm{ZnO}$ and Sintered $\mathrm{ZrO}_{2}$ and $\mathrm{TiO}_{2}$ Thin Films. Phys. Chem. Chem. Phvs. 2012, 14, 15429-15437.

(25) Huber, R.; Moser, J.-E.; Grätzel, M.; Wachtveitl, J. Real-Time Observation of Photoinduced Adiabatic Electron Transfer in Strongly Coupled Dye/Semiconductor Colloidal Systems with a 6 fs Time Constant. I. Phvs. Chem. B 2002, 106, 6494-6499.

(26) Feldt, S. M.; Wang, G.; Boschloo, G.; Hagfeldt, A. Effects of Driving Forces for Recombination and Regeneration on the Photovoltaic Performance of Dye-Sensitized Solar Cells Using Cobalt Polypyridine Redox Couples. I. Phys. Chem. C 2011, 115, 2150021507.

(27) Lanzani, G. The Photophvsics Behind Photovoltaics and Photonics: Wiley: 2012.

(28) Chekalin, S. V.; Yartsev, A. P.; Sundström, V. The Primary Stages of the Charge Carrier Photogeneration in $\mathrm{C}_{60}$ Films Studied by the 100-fs Laser Pulse Pump-Probe Method. I. Exp. Theor. Phys. 2001, 93, 706-716.
(29) Cappel, U. B.; Feldt, S. M.; Schöneboom, J.; Hagfeldt, A.; Boschloo, G. The Influence of Local Electric Fields on Photoinduced Absorption in Dye-Sensitized Solar Cells. I. Am. Chem. Soc. 2010, 132, 9096-9101.

(30) Ren, Y.; Hiszpanski, A. M.; Whittaker-Brooks, L.; Loo, Y.-L. Structure-Property Relationship Study of Substitution Effects on Isoindigo-Based Model Compounds as Electron Donors in Organic Solar Cells. ACS Appl. Mater. Interfaces 2014, 6, 14533-14542.

(31) Cappel, U. B.; Moia, D.; Bruno, A.; Vaissier, V.; Haque, S. A.; Barnes, P. R. F. Evidence for Photo-Induced Charge Separation between Dye Molecules Adsorbed to Aluminium Oxide Surfaces. Sci. Rep. 2016, 6, 21276.

(32) Pope, M.; Swenberg, C. E. Electronic Processes in Organic Crystals and Polymers; Oxford University Press: 1999.

(33) Schuller, J. A.; Karaveli, S.; Schiros, T.; He, K.; Yang, S.; Kymissis, I.; Shan, J.; Zia, R. Orientation of Luminescent Excitons in Layered Nanomaterials. Nat. Nanotechnol. 2013, 8, 271-276.

(34) Magri, A.; Friederich, P.; Schäfer, B.; Fattori, V.; Sun, X.; Strunk, T.; Meded, V.; Hueso, L. E.; Wenzel, W.; Ruben, M. Charge Carrier Mobility and Electronic Properties of $\mathrm{Al}(\mathrm{Op})_{3}$ : Impact of Excimer Formation. Beilstein I. Nanotechnol. 2015, 6, 1107-1115.

(35) Köhler, A.; Bässler, H. Electronic Processes in Organic Semiconductors: An Introduction; Wiley: 2015.

(36) Guo, Z.; Lee, D.; Schaller, R. D.; Zuo, X.; Lee, B.; Luo, T.; Gao, H.; Huang, L. Relationship between Interchain Interaction, Exciton Delocalization, and Charge Separation in Low-Bandgap Copolymer Blends. I. Am. Chem. Soc. 2014, 136, 10024-10032.

(37) Katoh, R.; Sinha, S.; Murata, S.; Tachiya, M. Origin of the Stabilization Energy of Perylene Excimer as Studied by Fluorescence and near-Ir Transient Absorption Spectroscopy. L. Photochem. Photobiol. A 2001, 145, 23-34.

(38) Furube, A.; Murai, M.; Tamaki, Y.; Watanabe, S.; Katoh, R. Effect of Aggregation on the Excited-State Electronic Structure of Perylene Studied by Transient Absorption Spectroscopy. I. Phvs. Chem. A 2006, 110, 6465-6471.

(39) Moser, J.-E. Dynamics of Interfacial and Surface Electron Transfer Processes. In Dye-Sensitized Solar Cells; Kalyanasundaram, K., Ed.; EFPL Press: Lausanne, Switzerland, 2010.

(40) Barzykin, A.; Tachiya, M. Mechanism of Charge Recombination in Dye-Sensitized Nanocrystalline Semiconductors: Random Flight Model. I. Phys. Chem. B 2002, 106, 4356-4363.

(41) Haque, S. A.; Tachibana, Y.; Willis, R. L.; Moser, J. E.; Grätzel, M.; Klug, D. R.; Durrant, J. R. Parameters Influencing Charge Recombination Kinetics in Dye-Sensitized Nanocrystalline Titanium Dioxide Films. I. Phvs. Chem. B 2000, 104, 538-547.

(42) Rothenberger, G.; Moser, J.; Grätzel, M.; Serpone, N.; Sharma, D. K. Charge Carrier Trapping and Recombination Dynamics in Small Semiconductor Particles. I. Am. Chem. Soc. 1985, 107, 80548059.

(43) McEvoy, A. J.; Castaner, L.; Markvart, T. Solar Cells: Materials, Manufacture and Operation; Academic Press: 2012.

(44) Yum, J. H.; Moon, S. J.; Humphry-Baker, R.; Walter, P.; Geiger, T.; Nüesch, F.; Grätzel, M.; Nazeeruddin, M. K. Effect of Coadsorbent on the Photovoltaic Performance of Squaraine Sensitized Nanocrystalline Solar Cells. Nanotechnology 2008, 19, 424005 .

(45) Yen, Y.-S.; Lin, T.-Y.; Hsu, C.-Y.; Chen, Y.-C.; Chou, H.-H.; Tsai, C.; Lin, J. T. A Remarkable Enhancement of Efficiency by CoAdsorption with Cdca on the Bithiazole-Based Dye-Sensitized Solar Cells. Org. Electron. 2013, 14, 2546-2554.

(46) Wang, Z.-S.; Cui, Y.; Dan-oh, Y.; Kasada, C.; Shinpo, A.; Hara, K. Thiophene-Functionalized Coumarin Dye for Efficient DyeSensitized Solar Cells: Electron Lifetime Improved by Coadsorption of Deoxycholic Acid. I. Phys. Chem. C 2007, 111, 7224-7230. 



\section{Donor Effect on Photoinduced Interfacial Charge Transfer Dynamics for D- $\pi$-A Diketopyrrolopyrole Dye-Sensitizers Adsorbed on Titanium Dioxide}

\section{Supporting Information}

Hee Won Bahng, ${ }^{1,3}$ Anders Hagfeldt, ${ }^{2,3}$ and Jacques-E. Moser ${ }^{1,3} *$

${ }^{1}$ Photochemical Dynamics Group, Institute of Chemical Sciences \& Engineering, École polytechnique fédérale de Lausanne, 1015 Lausanne, Switzerland

${ }^{2}$ Laboratory of Photomolecular Science, Institute of Chemical Sciences \& Engineering, École polytechnique fédérale de Lausanne, 1015 Lausanne, Switzerland

${ }^{3}$ Lausanne Centre for Ultrafast Science (LACUS), École polytechnique fedérale de Lausanne, 1015 Lausanne, Switzerland

* Corresponding author : E-mail : je.moser@epfl.ch 

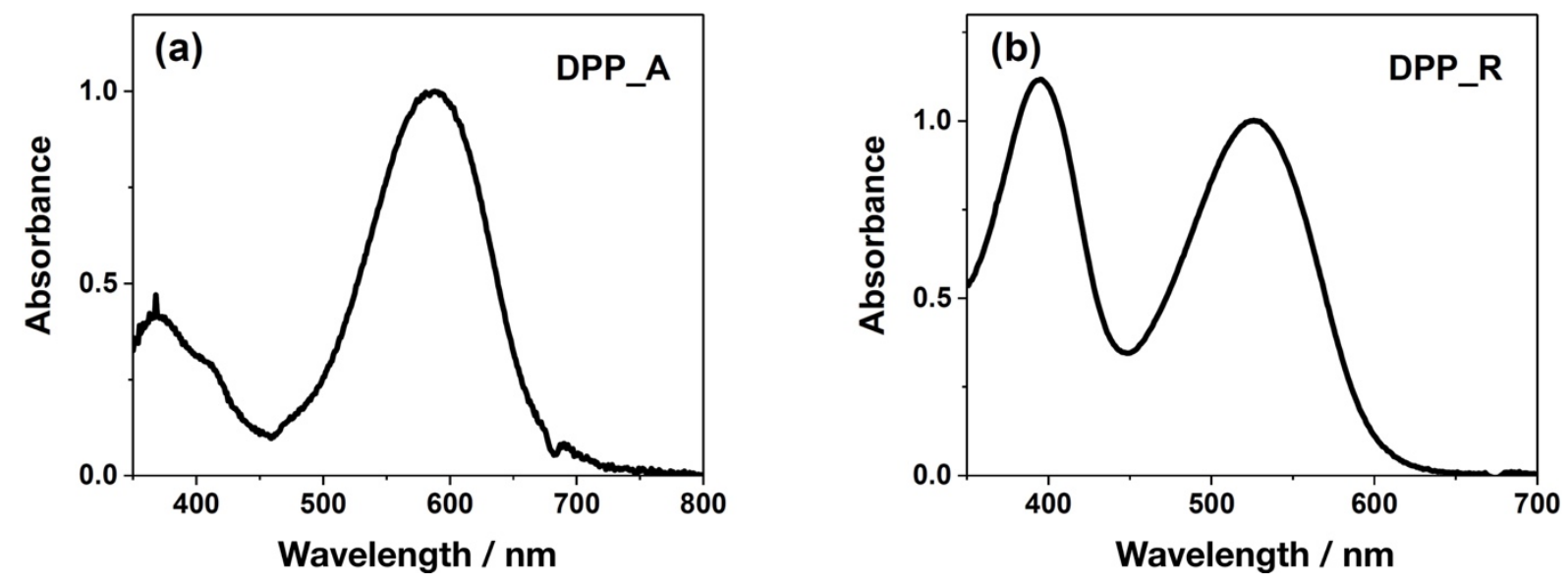

Figure S1. Normalized steady-state absoprtion spectra of $\mathbf{D P P} \_\mathbf{A}$ (a) and DPP_R (b) dissolved in 4-tert-butanol/acetonitrile mixture $(1: 1 \mathrm{v} / \mathrm{v})$ and 4-tert-butanol, respectively. 
DPPA
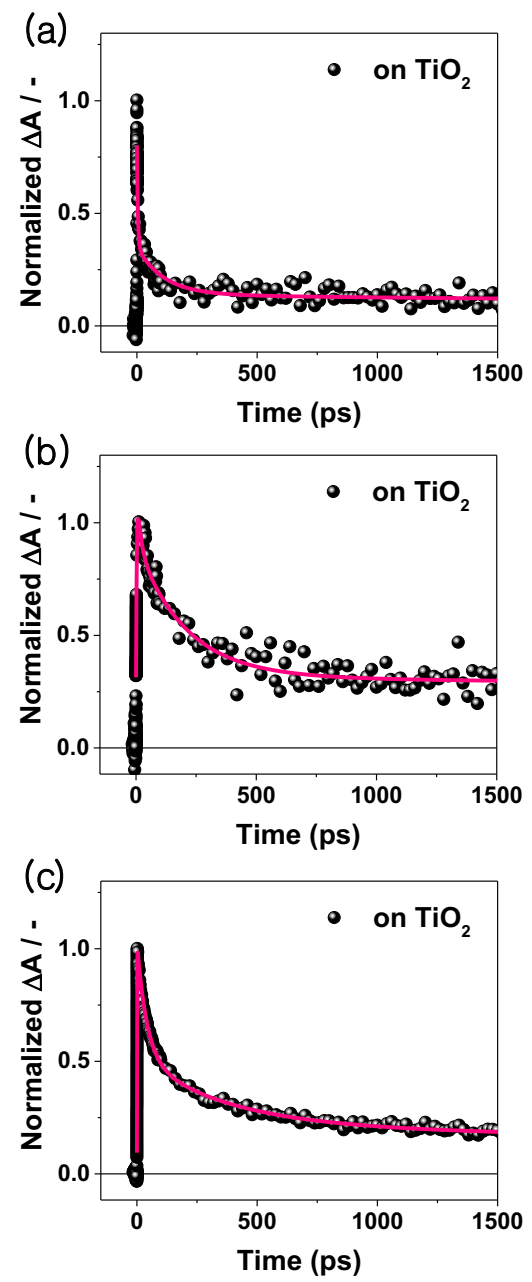
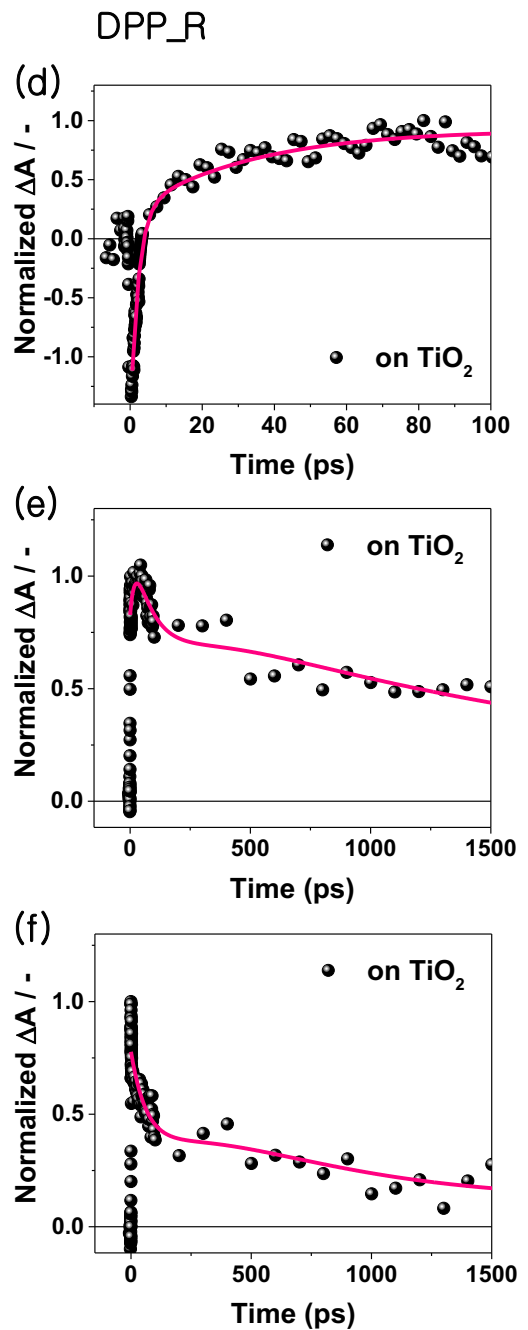

Figure S2. fs-TA decay profiles of DPP_A and DPP_R on $\mathrm{TiO}_{2}$ film pumped at $600 \mathrm{~nm}$ (a-c) and $530 \mathrm{~nm}$ (d-f), respectively, with $28 \mu \mathrm{J} / \mathrm{cm}^{2}$. Each profile of DPP_A was probed at $470 \mathrm{~nm}$ (a) $760 \mathrm{~nm}$ (b) $705 \mathrm{~nm}$ (c) and DPP_R was probed at $680 \mathrm{~nm}$ (d) $750 \mathrm{~nm}$ (e) $630 \mathrm{~nm}$ (f). The films prepared by dipping in the dye bath with $1: 50$ dye to CDCA ratio and all profiles are normalized by maximum intensity. 
Table S1. Transient absorption decay parameters, time constants $\left(\tau_{i}\right)$ and their fractional amplitudes $\left(\mathrm{A}_{i}\right)$ for DPP_A and DPP_R on mesoporous $\mathrm{TiO}_{2}$ films excited by $600 \mathrm{~nm}$ and $530 \mathrm{~nm}$, respectively. ${ }^{\mathrm{a}}$ The films were prepared by dipping in the dye bath with $1: 50$ dye to CDCA.

\begin{tabular}{|c|c|c|c|c|c|c|}
\hline & & & $\begin{array}{c}\tau_{1} / A_{1} \\
(p s / \%)\end{array}$ & $\begin{array}{c}\tau_{2} / A_{2} \\
(\mathrm{ps} / \%)\end{array}$ & $\begin{array}{c}\tau_{3} / \mathbf{A}_{3} \\
(\mathrm{ps} / \%)\end{array}$ & $\begin{array}{c}\tau_{4} / \mathbf{A}_{4} \\
(\mathrm{ps} / \%)\end{array}$ \\
\hline \multirow{3}{*}{ DPP_A } & \multirow{3}{*}{ On $\mathrm{TiO}_{2}$} & $470 \mathrm{~nm}$ & $4 / 65.7$ & $110 / 29.3$ & $>1.5 \mathrm{~ns} / 5.0$ & \\
\hline & & $760 \mathrm{~nm}$ & 0.6 (rise) & $40 / 56.3$ & $350 / 33.8$ & $>1.5 \mathrm{~ns} / 9.9$ \\
\hline & & $705 \mathrm{~nm}$ & 3.0 (rise) & $15 / 34.3$ & $200 / 60$ & $>1.5 \mathrm{~ns} / 5.7$ \\
\hline \multirow{3}{*}{ DPP_R } & \multirow{3}{*}{ On $\mathrm{TiO}_{2}$} & $680 \mathrm{~nm}$ & 20 (rise) / 30.8 & 150 (rise) / 69.2 & $100 / 61.9$ & $>1.5 \mathrm{~ns} / 38.1$ \\
\hline & & $750 \mathrm{~nm}$ & 320 (rise) & $70 / 16.1$ & $500 / 38.7$ & $>1.5 \mathrm{~ns} / 45.2$ \\
\hline & & $630 \mathrm{~nm}$ & 2.2 (rise) / 71.0 & 35 (rise) / 29.0 & $>1.5 \mathrm{~ns}$ & \\
\hline
\end{tabular}



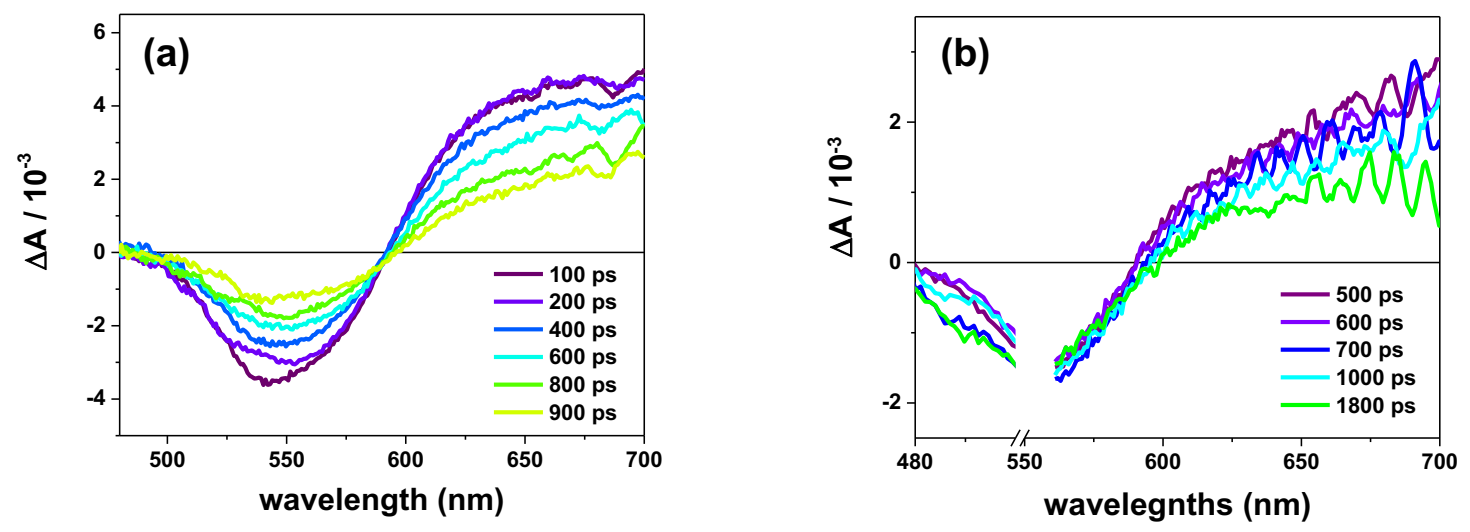

Figure S3. fs-TA spectra of DPP_R on $\mathrm{TiO}_{2}$ film at different optical delays, which were excited at $390 \mathrm{~nm}$ (a) with $<28 \mu \mathrm{J} / \mathrm{cm}^{2}$, showing gradual red-shift and the trend was also observed in the results performed by $530 \mathrm{~nm}$ (b) excitation source. 


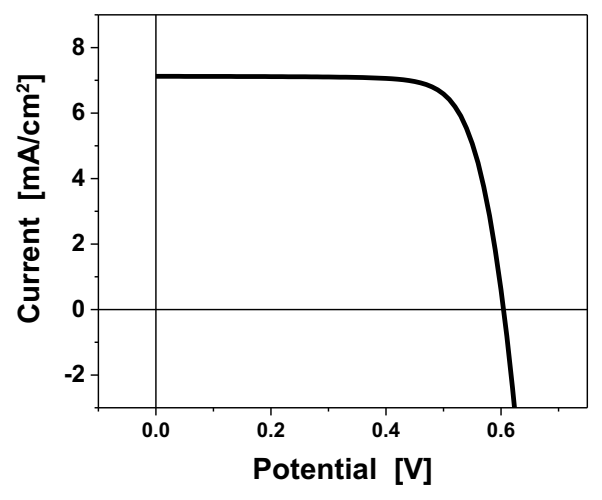

\begin{tabular}{ccccc}
\hline & $\mathrm{V}_{\text {oc }}(\mathrm{V})$ & $\mathrm{J}_{\mathrm{sc}}\left(\mathrm{mA} / \mathrm{cm}^{2}\right)$ & $\mathrm{FF}$ & $\mathrm{PCE}(\%)$ \\
\hline DPP_R & 0.60 & 7.03 & 0.761 & 3.23 \\
\hline
\end{tabular}

Figure S4. The photocurrent density versus voltage curves (top) and photovoltaic characteristics (bottom) such as open circuit voltage $\left(\mathrm{V}_{\mathrm{oc}}\right)$, current density $\left(\mathrm{J}_{\mathrm{sc}}\right)$, fill factor $(\mathrm{FF})$ and power conversion efficiency (PCE) of DPP_R sensitized dye cell under standard AM1.5 irradiation. The electrolyte was composed of $0.6 \mathrm{M}$ 1,3-dimethylimidazolium iodide, $0.5 \mathrm{M}$ tert-butylpyridine, $0.03 \mathrm{M}$ iodine, $0.05 \mathrm{M}$ Lil, $0.1 \mathrm{M}$ GuNCS in 15/85 (v/v) mixture of valeronitrile and acetonitrile. The mesoporous $\mathrm{TiO} 2$ film was composed of a $4.5 \mathrm{~mm}$-thick transparent layer composed of anatase nanoparticles covered by a $4 \mathrm{~mm}$-thick scattering layer made of larger titania particles. For the counter electrode, a platinized counter electrode was used and it was assembled to the dye-adsorbed $\mathrm{TiO}_{2}$ electrode by hotmelt ionomer film, Surlyn (25 $\mu \mathrm{m}$, DuPont). 


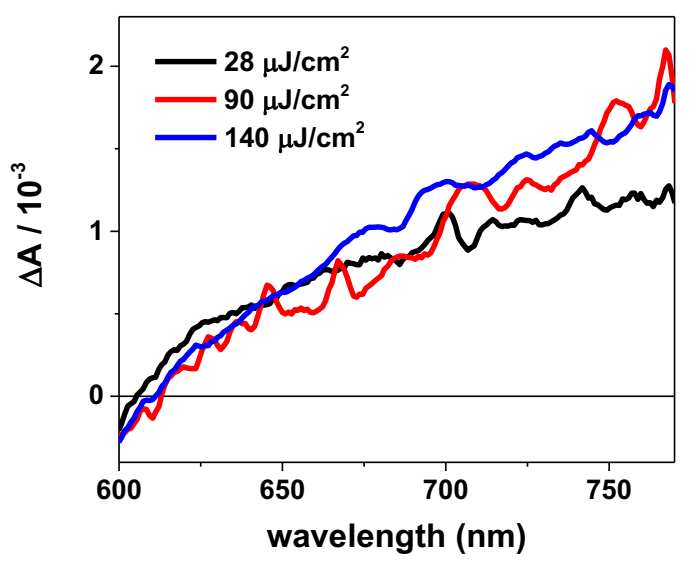

Figure S5. fs-TA spectra of DPP_R on $\mathrm{TiO}_{2}$ films at $0.8 \mathrm{ps}$, which were excited at $390 \mathrm{~nm}$ with energy fluences varying from 28 to $140 \mu \mathrm{J} / \mathrm{cm}^{2}$. Each spectrum was normalized by a maximum intensity of ground state band. 